\title{
Structurally-consistent estimation of use and non-values for landscape-wide environmental change
}

Authors: Brett Day1,*, Ian Bateman¹, Amy Binner ${ }^{1}$, Silvia Ferrini1 ${ }^{1,2,3}$ and Carlo Fezzi1,4

${ }^{1}$ Land Environment Economics \& Policy Institute, Department of Economics, University of Exeter, Exeter, EX4 4PU, UK

2 Centre for Social and Economic Research on the Global Environment, School of Environmental Sciences, University of East Anglia, Norwich, NR4 7TJ, UK

${ }^{3}$ University of Siena, Department of Political Science and International, Italy

${ }^{4}$ Department of Economics and Management, University of Trento, Via Vigilio Inama, 5, 38122,

Trento, Italy

* Corresponding Author: brett.day@exeter.ac.uk Tel: +44 (0)1932 723178.

Acknowledgements: This research was supported by NERC-funded ADVENT (NE/M019713) and CoastWEB (NE/N013573) projects and makes use of data collected for the EU DG Research funded project AquaMoney (SSPI- 022723) 


\begin{abstract}
We address the problem of estimating the use and nonuse value derived from a landscape-wide programme of environmental change. Working in the random utility framework, we develop a structural model that describes both demand for recreational trips to the landscape's qualitydifferentiated natural areas and preferences over different landscape-wide patterns of environmental quality elicited in a choice experiment. The structural coherence of the model ensures that the parameters of the preference function can be simultaneously estimated from the combination of revealed and stated preference data. We explore the properties of the model in a Monte Carlo experiment and then apply it to a study of preferences for changes in the ecological quality of rivers in northern England. This implementation reveals plausible estimates of the use and nonuse parameters of the model and provides insights into the distance decay in those two different forms of value.
\end{abstract}

Keywords: random utility models; nonuse utility; structural modelling; water quality; recreation; travel cost model; choice experiment 


\section{Introduction}

The problem addressed by this paper concerns the appraisal of programmes or policies whose environmental impacts are not constrained to a particular site but which have widespread yet spatially-differentiated impacts across a landscape. Our motivating example concerns a programme designed to improve the ecological status of a region's rivers ${ }^{1}$, a change that delivers benefit flows not only through improved recreational experiences at riverside sites but also, potentially, through increased nonuse value.

Valuing a programme that delivers a simultaneous change in the quality of natural areas across a landscape presents a significantly more complex challenge than the single-site appraisal problem. With respect to recreational use, perhaps, the most significant of those challenges is in understanding how individuals assess the value of a landscape offering a multiplicity of recreational opportunities. In the recreational demand literature, that problem is most frequently approached through adoption of the discrete choice travel cost (TC) method, a revealed preference (RP) approach that derives estimates of value from examination of recreational choice behaviour. Discrete choice TC modelling is theoretically underpinned by the random utility maximisation (RUM) model (McFadden, 1973) which formally defines the structure of individuals' preferences and the process through which individuals choose which of the set of quality-differentiated recreational destinations to visit. Armed with estimates of the preference function derived from a clear structural model of behaviour, TC analysts can explore the potential welfare consequences that might arise should environmental quality change in a variety of different ways across any number of sites in a landscape.

While the discrete-choice TC model has many advantages it also has shortcomings. One obvious shortcoming is that the technique is unable to estimate value derived from nonuse. Moreover, reliance on observed behaviour may result in problems of identification, for example, when the range of current qualities fails to cover that to be evaluated under the proposed programme. An alternative method that addresses both those shortcomings is provided by stated preference (SP) methods of valuation.

\footnotetext{
1 Other similar programmes include agri-environment schemes that deliver regional changes in agricultural landscapes, air quality regulations that tighten controls over regional air pollution sources and hazardous waste clean-up programs that rehabilitate an array of contaminated locations.
} 
In theory, an SP approach could generate data that would allow identification of both use and nonuse values for any desired pattern of environmental quality change. Realising that outcome is, of course, more difficult. One problem concerns how to convey to respondents the complex spatial reality of the landscape within which hypothetical changes in environmental quality occur. As we discuss further in Section 2, here we champion the use of visual spatial choice experiments (VSCEs), an SP elicitation method in which respondents are asked to choose between policy options presented to them in the form of maps displaying the environmental quality delivered by a policy at each location in the landscape. This use of spatial visualisation provides a mechanism whereby complex differences in the spatial organisation of supply under different policy options can be conveyed to respondents in a simple and accessible manner.

A second complexity, concerns analysis of responses to SP exercises like the VSCE. The particular difficulty here is that the preferences underpinning those responses reflect value in use and nonuse and are shaped by the substitution possibilities afforded by the diversity of natural areas present in a landscape. As we describe in Section 2, to date, the analysis of SP data has failed to convincingly address these complexities. Analysts have tended to forego the formality of structural modelling relying instead on highly reduced-form specifications which confound use and nonuse value and address issues of spatial location and substitution through estimation of 'distance-decay' parameters and broad indices of substitute availability and quality.

The core contribution of this paper is to propose an estimation strategy that directly addresses these issues. In Section 3 we describe a formulation for the preference function that captures both use and nonuse values. Moreover we show how within the RUM framework, that specification can be developed into a coherent structural model of choice behaviour that not only describes respondents' observed recreational activity but also their choices in a VSCE exercise. Indeed, one significant advantage of our approach is that it results in econometric specifications for both observed recreational behaviour and VSCE responses that are derived from the same structural model. This common derivation has the added benefit of allowing RP and SP data to simultaneously inform estimation of the same structural parameters.

As we describe in Section 4, deriving our econometric specification from a structural model, results in a preference function that is nonlinear in the structural parameters. Moreover, unlike most previous applications of the RUM approach, our structurally-derived model results 
in error terms that are sums of independent logistic variates. Given these complexities, in Section 5, we present the results of a Monte Carlo experiment in which we explore the circumstances under which the model can successfully recover estimates of the preference parameters. Finally, in Section 6, we estimate the model in the context of a real data set collected in a large scale survey carried out across Northern England. This implementation reveals intuitively plausible estimates of the use and nonuse parameters of the model and provides interesting insights into the distance decay in those two different forms of value.

As we describe in detail in the next section, our paper makes contributions to a number of literatures. Primarily, it makes a contribution to the field of structural econometric modelling in environmental economics (Timmins and Schlenker, 2009). As far as the authors are aware, we provide the first attempt to underpin the analysis of non-market valuation data for landscapes of quality-differentiated sites with a coherent structural description of use and nonuse value. In that way, our approach builds on the structurally-coherent model developed by Eom and Larson (2006) to explore use and nonuse values in the single site setting. Moreover, in providing a new approach to the simultaneous analysis of TC and CE data, our work makes a novel contribution to the literature on the combined analysis of RP and SP data (Whitehead et al., 2008). Our paper is also of interest to the field of discrete choice modelling, presenting as it does a RUM specification not previously explored in the literature. Finally, our research contributes to SP research by showing how issues of distance decay, substitute location and quality as well as use and nonuse value can be coherently addressed through utility-theoretic modelling of preferences.

\section{Literature Review and Contribution}

There is a long history of applying SP methods to the problem of valuing spatially-explicit environmental quality change. Early applications used the contingent valuation method and focused on valuing environmental quality change at some particular location (Davis and Knetsch, 1966; Oster, 1977). The same problem has since been examined through application of the choice experiment (CE) method, an approach that allows analysts to derive a richer description of values for different dimensions of quality change at the focus location (e.g. Boxall et al., 1996; Hanley et al., 1998). More recently, SP methods have been applied in efforts to value more complex patterns of landscape-wide environmental change (e.g. Brouwer et al., 2010; Meyerhoff et al., 2014).

In stark contrast to the structural coherence of the RUM model underpinning discrete 
choice TC modelling, analysis of responses to SP studies has almost universally adopted extreme reduced-form descriptions of preferences. In those studies, preferences are described as a simple, often linear, value function relating willingness to pay (WTP) to the level of environmental quality change and a variety of qualifiers. While many analysts include amongst those qualifiers measures of the distance from a respondent's home to the site of the environmental change (e.g. Bateman et al., 2006; Concu, 2007; Hanley et al., 2003; Sutherland and Walsh, 1985), few use the trip expenditure measure that is so central to the structural model of recreational-value formation used in TC analysis ${ }^{2}$. One possible justification for using a distance rather than travel cost measure is that SP surveys capture value flows derived both in use and nonuse. While, all else equal, use values must fall with increasing distance as a consequence of the rising costs of access, the same expectation is not self-evident for nonuse values (Bateman et al., 2006). Indeed, the empirical evidence for distance decay in nonuse values is mixed and based almost entirely on studies that have compared values expressed by those that currently use the resource (users) with those that currently do not (nonusers). Hanley et al. (2003), for example, find that values for users decay more rapidly than those for nonusers while Bateman et al. (2006) find no distance decay for nonusers in one study and comparable levels of distance decay for users and nonusers in another. Of course, values of users and nonusers should not be conflated with use values and nonuse values; for a start, it would be unreasonable to assume that current users of a resource do not also hold nonuse values. Indeed, Cummings and Harrison (1995) argue that a shortcoming of SP methods is that they fail to provide an operationally meaningful mechanism by which use and nonuse values can be separately identified.

A central contribution of our paper is to present a method of analysis that overcomes the Cummings and Harrison (1995) critique. As we describe shortly, our method derives from a clear structural representation of preferences for use and nonuse that progresses to a method of estimation that allows for separate identification of distance decay effects from use and nonuse. In line with the structural model, use value is assumed to decay with the costs of access while we use a flexible functional form to investigate whether and how nonuse value decays with distance.

Even less structurally convincing than the treatment of distance is the way in which SP

\footnotetext{
2 Though some authors have used travel time, a close correlate of travel cost (e.g. Jørgensen et al., 2013; Taylor and Longo, 2010) .
} 
studies have addressed the issue of substitutes. Indeed, many SP studies simply ignore the issue altogether (amongst many others; Birol et al., 2006; Doherty et al., 2014; Hanley et al., 2003; Stithou et al., 2013). Where attempts have been made to control for substitute availability those controls tend to have been included in the model specification in ways that bear little resemblance to any formal model of recreational demand behaviour. Often that means including some aggregate measure of the quantity or density of environmental assets in the vicinity of a respondent's home (e.g. De Valck et al., 2017; Pate and Loomis, 1997; Yao et al., 2014) or the proximity of the nearest substitute (e.g. Caudill et al., 2011; Söderberg and Barton, 2014).

Of course, the influence of substitutes on values is not only determined by the proximity of alternative sites but also by their quality. While the discrete choice TC model explicitly incorporates the quality of each substitute into its description of recreational demand behaviour, the question of substitute quality has, until recently, received little attention in the SP literature. Part of the problem has been in finding methods to present respondents with descriptions of complex spatial patterns of quality-differentiated substitute locations. Recently, a growing number of studies have sought to address those difficulties by depicting the context of substitutes and their qualities on colour-coded and annotated maps (e.g. Brouwer et al., 2010; Kataria et al., 2012; Schaafsma and Brouwer, 2013; Söderberg and Barton, 2014) ${ }^{3}$. The particular map-based SP elicitation method we explore in this paper is similar to that used by Horne et al. (2005) and Meyerhoff et al. (2014). In those studies, respondents are presented with a selection of maps each illustrating a different spatial pattern of quality change and each associated with some particular cost. Respondents are asked to identify which costly pattern of quality change is their most preferred. We describe this form of CE as a visual spatial choice experiment (VSCE). By way of illustration, Figure 1, depicts a VSCE choice task from the empirical application that we investigate in Sections 6 and 7 of this paper. In this application, respondents are given a choice between two states of the world which differ in terms of the spatial pattern of river water quality and a coercive cost borne by their household.

\footnotetext{
${ }^{\text {e3 }} \mathrm{A}$ number of these map-based SP studies stem from the same EU-funded project (Aquamoney) which sought evidence on the value of landscape-wide water quality improvement in order to inform implementation of the EU's Water Framework Directive. Indeed, the empirical case study we describe subsequently is part of that same effort.
} 


\section{[INSERT FIGURE 1 AROUND HERE]}

Map-based presentations like the VCSE allow SP studies to elicit preferences for complex landscape-wide patterns of environmental change, explicitly presenting respondents with information on the quality and location of substitutes upon which they may condition their responses. How those responses should be modelled to properly reflect respondents' decision processes, however, remains an open question in the SP literature. Perhaps the most complete representation of substitute quality and location in that literature is that provided by Meyerhoff et al. (2014) who adopt a reduced-form specification in which distance decay parameters are estimated specific to each level of quality change at each site, though that focus on identifying site-specific parameters inhibits effective transfer of value estimates outside the study area.

The central contribution of this paper is to build an econometric specification for the analysis of VSCE data that is derived from a coherent structural model of preferences for landscape-wide environmental quality change. In that pursuit, our starting point is the RUM model used in discrete-choice TC studies to describe the preferences that drive recreational choices over substitute, quality-differentiated sites. Accordingly, our work has parallels to the contingent behaviour literature (e.g. Adamowicz et al., 1994; Christie et al., 2007; Englin and Cameron, 1996; Whitehead et al., 2000) which combines observed recreational behaviour with SP data recording how respondents report they would behave if the qualities or availability of recreation sites were to change. Since the SP and RP data are assumed to be driven by the same choice process, the same structural modelling can be applied directly to the combined data allowing both types of data to inform identification of the parameters of the model. Our work extends that same estimation strategy to SP data derived from a VSCE exercise thereby contributing to efforts in the field of non-market valuation to combine RP and SP data in model estimation stretching back at least as far as Cameron (1992) and Adamowicz et al. (1994).

Contingent behaviour studies are limited to identifying information on preferences for recreational use. The method we outline is for application to VSCE data that contains expressions of preferences reflecting not only use values, but also values from nonuse. Accordingly, our model of responses to VSCE exercises has to incorporate a structural description for nonuse utility into the preference specification. In recovering preferences for environmental quality in both use and nonuse, our work is comparable to that of Eom and Larson (2006). Those authors explore the 
decomposition of total value into use and nonuse value in the context of valuing a single recreational site. Indeed, they begin with a particular specification of the Marshallian tripdemand function for that site and integrate back to reveal the form of the quasi-expenditure function, interpreting the constant of integration as the source of nonuse value. In a sense, the approach we develop in this paper can be considered as the discrete choice counterpart to the continuous demand model developed by Eom and Larson (2006) and one that moves away from the focus on a single site to consider the complexities of environmental valuation in the context of a landscape of quality-differentiated sites ${ }^{4}$.

Of course, it would be possible to develop a demand system analogue to Eom and Larson's single equation model with nonuse values entering through the constant of integration. Remaining in 'product space' in which each site is treated as a separate good within the demand system, however, raises a number of complexities particularly when the landscape is endowed with a large number of such sites. In such cases, problems of parameter dimensionality quickly arise with, for example, the number of cross-price elasticity terms rising quadratically with the number of sites. Those complexities may be confounded by data issues, for example, demand functions may be difficult to identify when households typically make few or no visits to each different site. Moreover, data often contains limited or no variation in each site's environmental quality making it infeasible to identify own- and cross-quality terms. A final difficulty with analysing demand in product space is that it returns specific estimates for the particular set of study sites, but does not provide a ready method for transferring those findings to explore the values generated by new sites or by alternative landscapes with a different set of sites.

In contrast, the discrete-choice approach that we adopt in this paper, models demand in 'characteristic space' rather than 'product space'. That approach assumes that a site can be described as a bundle of physical characteristics including its environmental qualities and that households have preferences over bundles of characteristics of sites, and not for sites per se. Moreover, in one choice period households take at most one trip, choosing where to visit from

\footnotetext{
${ }^{4}$ Note that Eom and Larson (2006) acknowledge that the river basin which forms the subject of their investigation, consists of a variety of different sites, visits to six of which are elicited in their survey. Rather than estimating a system of demand equations for these substitute sites, Eom and Larson (2006) choose to focus on estimating the value for a "typical site", defining the level of demand for that typical site as the number of visits a respondent takes to their most frequently visited site.
} 
the set of quality-differentiated recreation sites. This discrete-choice approach solves most of the problems associated with estimating demand systems in product space. First, it deals naturally with data in which households demand few or no trips to each site. Second, the number of parameters is limited by the number of characteristics and does not rise with the number of sites. Third, the approach explicitly embraces substitution possibilities naturally capturing both crossprice and cross-quality effects. Finally, the approach lends itself to transfer exercises that look to value the introduction of new sites into the landscape or to explore values generated by other landscapes with different spatial patterns of quality-differentiated sites.

\section{The Structural Model}

The data we wish to interrogate reports on the preferences of a sample of individuals indexed $i=1,2, \ldots, N$, living in a region endowed with an assortment of natural areas, indexed $j=1,2, \ldots, J$. The welfare that an individual realises from those natural areas during time period $t$ arises as a result of the qualities that those areas exhibit; our particular interest being their environmental qualities. Qualities differ across natural areas and may differ across time periods, though are assumed to remain constant for the duration of any one period. The qualities of natural areas can also differ across possible states of the world, $s=0,1, \ldots, S$. The reality of the current state of the world is indicated $s=0$ and the $S$ alternative states of the world are those constructed to describe the qualities of natural areas for the purposes of a non-market valuation exercise. The qualities of natural area $j$, under scenario $s$ is given by the vector $\boldsymbol{q}_{j, s}$, where for simplicity of notation we have assumed that quality remains constant across time.

Natural areas can be used for outdoor recreation, though to enjoy the recreational experience offered by natural area $j$, an individual must make the round trip to that location. We indicate the consumption levels of those trips by the vector $\boldsymbol{x}_{i, t, s}=\left(x_{i, 1, t, s}, x_{i, 2, t, s}, \ldots, x_{i, J, t, s}\right)$ and take those to be goods whose purchase prices (comprising the costs of travel and the opportunity cost of travel time) are identified by the price vector $\boldsymbol{p}_{i}=\left(p_{i, 1}, p_{i, 2}, \ldots, p_{i, J}\right)$.

Individuals might also gain utility from natural areas without having to purchase any complementary market goods; perhaps simply from knowing that such natural areas exist or that others may benefit from their existence. ${ }^{5}$ Again we assume that utility derived in this way arises

\footnotetext{
${ }^{5}$ For simplicity of notation, we assume that all natural areas are accessible. Individuals may gain nonuse
} 
as a consequence of the qualities of a natural area. ${ }^{6}$ Following evidence from the SP literature (Bateman et al., 2006; Schaafsma et al., 2012) we allow for the possibility that the nonuse value derived from a natural area with particular qualities may differ with distance to an individual's home and identify those distances by the vector $\boldsymbol{d}_{i}=\left(d_{i, 1}, d_{i, 2}, \ldots, d_{i, J}\right) \cdot{ }^{7}$

Our structural model starts with the assumption that the direct utility function takes the following separable form:

$$
U\left(U^{u s e}\left(\boldsymbol{x}_{i, t, s}, \boldsymbol{q}_{1, s}, \ldots, \boldsymbol{q}_{J, s}\right), U^{\text {nonuse }}\left(\boldsymbol{q}_{1, s}, \ldots, \boldsymbol{q}_{J, s}, \boldsymbol{d}_{i}\right), z_{i, t, s}\right) \quad(\forall i, t, s) .
$$

Thus utility flows from three sources; from the sub-utility function, $U^{\text {use }}(\cdot)$, in which the environmental quality of sites is combined with travel in order to deliver recreational use values, from the sub-utility function, $U^{\text {nonuse }}(\cdot)$, that delivers nonuse value simply through environmental quality and from other consumption captured by the composite good, $z_{i, t, s}$. We assume that utility is increasing in all three of those arguments. Moreover, we assume that $U^{u s e}(\cdot)$ exhibits weak complementarity such that the utility from use derived from the qualities of a natural area falls to zero when consumption of trips to that site is zero; that is to say, $\partial U^{u s e} / \partial \boldsymbol{q}_{j, s}=\mathbf{0}$ when $x_{j, t, s}=0$. We also assume that preferences are strongly separable over time.

If the choice period is reduced to a length of time such that in each period, $t$, an individual can make at most one recreational trip, then an individual's consumption decision amounts to solving the discrete choice problem given by (Phaneuf and von Haefen, 2009);

$$
\begin{aligned}
& \max _{\boldsymbol{x}_{i, t, s}, z_{i, t, s}} U\left(U^{u s e}\left(\boldsymbol{x}_{i, t, s}, \boldsymbol{q}_{1, s}, \ldots, \boldsymbol{q}_{J, s}\right), U^{\text {nonuse }}\left(\boldsymbol{q}_{1, s}, \ldots, \boldsymbol{q}_{J, s}, \boldsymbol{d}_{i}\right), z_{i, t, s}\right) \\
& \text { s.t. } \quad y_{i, t}=\boldsymbol{p}_{i}^{\prime} \boldsymbol{x}_{i, t, s}+z \\
& x_{j, t, s} \in\{0,1\} \quad(\forall i, t, s) \\
& x_{j, t, s} x_{k, t, s}=0(\forall k \neq j)
\end{aligned}
$$

utility from sites even if they are not accessible for recreation, a fact that analysts might exploit in attempts to identify the separate contribution of environmental quality to utility in use and nonuse.

6 The qualities which deliver value in nonuse could potentially differ from those offering value in use. Our notation assumes, therefore, that the vector $\boldsymbol{q}_{j, s}$ is a comprehensive list of utility-relevant quality attributes, but that the contribution which a particular quality element makes to value in use or nonuse may be zero.

${ }^{7}$ In our empirical application we take those distances to be straight line measures. 
The conditional indirect utility function that arises from (2) takes the form;

$$
u_{i, t, s \mid j}=u\left(u^{u s e}\left(\boldsymbol{q}_{j, s}\right), u^{\text {nonuse }}\left(\boldsymbol{q}_{1, s}, \ldots, \boldsymbol{q}_{J, s}, \boldsymbol{d}_{i}\right), y_{i, t}-p_{i, j}\right) \quad(\forall i, t, s)
$$

Observe that our assumptions regarding weak complementarity, imply that an individual only derives use utility from the qualities of the natural area that they choose to visit in choice period $t$. In contrast, during that period individuals derive nonuse utility from the qualities of all natural areas. Our model of recreational behaviour is completed through the rational choice rule;

$$
\text { choose to visit } j \text { in period } t \text { if: } u_{i, t, s \mid j}>\left\{u_{i, t, s \mid k}\right\}_{\forall k \neq j} \quad(\forall i, t, s)
$$

Over the course of a year we assume that individuals face $t=1,2, \ldots, T$ recreational choice periods of equal length and that in each period individuals follow (4) in determining their recreational choice behaviour. Accordingly our model follows the tradition of repeated discrete choice models as per Morey et al. (1993).

The research we describe subsequently involves a VSCE exercise in which respondents are asked to consider alternative states of the world in which the qualities of the natural areas differ from those experienced in the current state of the world $(s=0)$. The quality changes described in each alternative state of the world $(s=1,2, \ldots, S)$ cannot be achieved without cost, a cost to which individuals must contribute through a hypothetical coercive annual charge $C_{s}$. Since the year is divided into $T$ equally-sized choice periods indexed $t=1,2, \ldots, T$ we assume that the annual payment can be equivalently expressed as a series of per period payments; $c_{S}=C_{S} / T$. Preferences for these different states of the world have the same fundamental structure, though the conditional indirect utility function (3) must be modified to include the hypothetical payment;

$$
u_{i, t, s \mid j}=u\left(u^{u s e}\left(\boldsymbol{q}_{j, s}\right), u^{\text {nonuse }}\left(\boldsymbol{q}_{1, s}, \ldots, \boldsymbol{q}_{J, s}, \boldsymbol{d}_{i}\right), y_{i, t}-p_{i, j}-c_{s}\right) \quad(\forall i, t, s)
$$

which reduces to (3) in the current state of the world since $c_{0}=0$;

In a typical hypothetical choice task, individuals are presented with a set of scenarios, $\mathbb{S}$, drawn from the $S$ scenarios constructed for the VSCE. Respondents are asked to indicate which scenario is their most preferred. According to our model, to make that choice, respondents must first solve the site visitation problem (4) for each time period such that their declared preference over hypothetical scenarios should be made according to the choice rule; 


$$
\text { choose } s \text { if: } \sum_{t=1}^{T} \max _{j}\left(u_{i, t, s \mid j}\right)>\left\{\sum_{t=1}^{T} \max _{j}\left(u_{i, t, r \mid j}\right)\right\}_{\forall r \neq s} \quad(s, r \in \mathbb{S})
$$

where the summation over the $T$ time periods in a year follows from our assumption of intertemporal additive separability of the utility function.

\section{The Econometric Model}

We develop our econometric model by first specifying a functional form for the conditional indirect utility function (4). For econometric convenience we make the assumption of additive separability;

$$
\begin{aligned}
u_{i, t, s \mid j} & =v_{i, t, s \mid j}^{\text {use }}+v_{i, t, s}^{\text {nonuse }}+v_{i, t, s \mid j}^{\text {other }}+\varepsilon_{i, j, t, s} \\
& =v_{i, t, s \mid j}+\varepsilon_{i, j, t, s} \quad(j=1,2, \ldots, J+1 \text { and } \forall i, t, s)
\end{aligned}
$$

Where $\varepsilon_{i, j, t, s}$ is an econometric error term introduced to capture the divergence between our model of conditional indirect utility $\left(v_{i, t, s \mid j}^{u s e}+v_{i, t, s}^{n o n-u s e}+v_{i, t, s \mid j}^{\text {other }}\right)$ and the individual's experienced utility $\left(u_{i, t, s \mid j}\right)$. As we elaborate below $v_{i, t, s \mid j}^{\text {other }}$ is a composite good expressed as expenditure on other goods conditional on choice of $j$. Moreover, we treat $\varepsilon_{i, j, t, s}$ as a compound error comprising an element reflecting the numerous unmodelled influences on use utility, $\epsilon_{i, j, t, s}^{u s e}$ and an element reflecting the numerous unmodelled influences on nonuse utility, $\epsilon_{i, t, s}^{\text {nonuse }}$, such that;

$$
\varepsilon_{i, j, t, s}=\epsilon_{i, j, t, s}^{u s e}+\epsilon_{i, t, s}^{\text {nonuse }} \quad(j=1,2, \ldots, J+1 \text { and } \forall i, t, s)
$$

Notice that since individuals derive nonuse utility from the $J$ environmental areas independent of their recreation activity, the nonuse error component is not dependent on their choice of which site to visit. Moreover we specify;

$$
v_{i, t, s \mid j}^{u s e}=\alpha_{i, j, t}+\boldsymbol{q}_{j, s} \boldsymbol{\beta}_{i} \quad(j=1,2, \ldots, J \text { and } \forall i, t, s)
$$

where $\alpha_{i, j, t}$ is a site-specific utility element and $\boldsymbol{\beta}_{i}$ is the vector of coefficients describing the marginal use utilities of site qualities. Of course, in any choice period an individual may choose 
not to make a recreational trip to a natural area. We give that option the index $J+1$, and specify the use utility from choosing that option as;

$$
v_{i, t \mid J+1}^{u s e}=\alpha_{i, J+1, t} \quad(\forall i, t)
$$

Observe that since this option does not involve visiting one of the $J$ natural areas, the use utility associated with choosing this option does not change across scenarios. We gather the parameters of the use element of individual $i$ 's utility into the vector $\boldsymbol{\theta}_{\boldsymbol{i}}^{\boldsymbol{u s e}}=\left[\begin{array}{lll}\alpha_{i, 1, t} \ldots & \alpha_{i, J+1, t} \boldsymbol{\beta}_{i}\end{array}\right]$;

Our model of the nonuse utility element of the preference function is given by;

$$
v_{i, t, s}^{\text {nonuse }}=\sum_{j=1}^{J}\left(d_{i, j}+1\right)^{\lambda_{i}}\left(a_{i, j, t}+\boldsymbol{q}_{j, s} \boldsymbol{b}_{i}\right) \quad(\forall i, t, s)
$$

where $d_{i, j}$ is the distance from individual $i$ 's home to area $j, a_{i, j, t}$ is an area-specific element contributing to nonuse utility, $\boldsymbol{b}_{i}$ is the vector of coefficients on site qualities and $\lambda_{i}$ is a parameter that establishes the rate of distance decay in nonuse utility. Notice from (11) that nonuse utility is specified as a distance-weighted sum across the nonuse utility provided by each individual natural area. The use of summation imposes the assumption that no substitution or complementarity relationships exist between sites in delivering nonuse value. The power function used to describe that distance weighting, nests a number of plausible specifications: for example, $\lambda_{i}=0$ suggests that nonuse utility does not decline with distance, while $\lambda_{i}=-1$ suggests that the nonuse utility declines inversely with distance. Again we use the notation $\boldsymbol{\theta}_{\boldsymbol{i}}^{\text {nonuse }}=\left[\begin{array}{llll}a_{i, 1, t} \ldots & a_{i, J, t} & \boldsymbol{b}_{i} & \lambda_{i}\end{array}\right]$ to denote parameters of the nonuse element of utility.

Finally we assume a simple linear form for utility from other consumption, such that conditional on travelling to $j$

$$
v_{i, t, s \mid j}^{o t h e r}=\gamma_{i}\left(y_{i, t}-p_{i, j}-c_{s}\right) \quad(j=1,2, \ldots, J+1 \text { and } \forall i, t, s) .
$$

We imagine a dataset, like that of the empirical exercise we describe subsequently, in which a sample of respondents provide both RP and SP data. The RP data details the visits each respondent made to the different natural areas over the course of the last year. The SP data is collected from a series of hypothetical choice tasks that, as described earlier, ask respondents to 
choose between quality-differentiated states of the world. Our objective is to build an econometric model that is derived from the coherent behavioural model described in equations (4) and (6) such that the parameters of the structural equations in equations (9), (10), (11) and (12) can be estimated simultaneously from both RP and SP data.

Our econometric model proceeds through building a likelihood in the manner of the standard RUM model. As a result of the error term $\varepsilon_{i, j, t, s}$, probabilistic behavioural equations replace the deterministic choices envisaged by (4) and (6). As such, our econometric model of the probability of observing individual $i$ choosing to visit site $j$ in period $t$ can be written as;

$$
\begin{aligned}
P_{i, j, t, 0}\left(\boldsymbol{\theta}_{i}^{\text {use }}, \gamma_{i}\right) & =\operatorname{Prob}\left[u_{i, t, 0 \mid j}>u_{i, t, 0 \mid k} \forall j \neq k\right] \\
& =\operatorname{Prob}\left[v_{i, t, 0 \mid j}^{u s e}+v_{i, t, 0}^{\text {nonuse }}+v_{i, t, 0 \mid j}^{\text {other }}+\epsilon_{i, j, t, 0}^{\text {use }}+\epsilon_{i, t, 0}^{\text {nonuse }}\right. \\
& \left.>v_{i, t, 0 \mid k}^{\text {use }}+v_{i, t, 0}^{\text {non-use }}+v_{i, t, 0 \mid k}^{\text {other }}+\epsilon_{i, k, t, 0}^{\text {use }}+\epsilon_{i, t, 0}^{\text {nonuse }} \quad \forall k \neq j\right] \\
& =\operatorname{Prob}\left[v_{i, t, 0 \mid k}^{\text {use }}+v_{i, t, 0 \mid k}^{\text {other }}-v_{i, t, 0 \mid j}^{\text {use }}-v_{i, t, 0 \mid j}^{\text {other }}>\epsilon_{i, j, t, 0}^{\text {use }}-\epsilon_{i, k, t, 0}^{\text {use }} \quad \forall k \neq j\right]
\end{aligned}
$$

Since individuals derive the same level of nonuse value independent of their choice of which area to visit, the nonuse element of modelled utility nets out of line 3 of equation (13). ${ }^{8}$ It follows, that the parameters determining values through nonuse cannot be estimated from discrete-choice data on recreational behaviour. In a similar vein, the differencing of errors, ensures that elements that relate to unmodelled influences on nonuse utility also net out of the errors in equation (13).

Probabilities for responses to the VCSE can be developed in a similar manner. In particular, in a VSCE with $M$ exercises indexed $m=1,2, \ldots, M$, the probability that individual $i$ chooses option $s$ from the choice set $\mathbb{S}_{m}$ amounts to;

\footnotetext{
${ }^{8}$ Since income, $y_{t, i}$, remains constant across choice options, the term $\gamma_{i} y_{t, i}$ from equation (12) also drops out of equation (13) as is true of all RUM applications assuming constant marginal utility of income.
} 


$$
\begin{aligned}
& P_{i, s, m}\left(\boldsymbol{\theta}_{\boldsymbol{i}}^{\text {use }}, \boldsymbol{\theta}_{\boldsymbol{i}}^{\text {non-use }}, \gamma_{i}\right)=\operatorname{Prob}\left[\sum_{t=1}^{T} \max _{j}\left(u_{i, t, s \mid j}\right)>\left\{\sum_{t=1}^{T} \max _{j}\left(u_{i, t, r \mid j}\right)\right\}_{\forall r \neq s}\right] \\
&=\operatorname{Prob}\left[\sum_{t=1}^{T} \max _{j}\left(v_{i, t, s \mid j}+\varepsilon_{i, j, t, s}\right)>\left\{\sum_{t=1}^{T} \max _{j}\left(v_{i, t, r \mid j}+\varepsilon_{i, j, t, r}\right)\right\}_{\forall r \neq s}\right] \\
&=\operatorname{Prob}\left[\sum_{t=1}^{T} \max _{j}\left(v_{i, t, s \mid j}^{\text {use }}+v_{i, t, s \mid j}^{\text {other }}+\epsilon_{i, j, t, s}^{\text {use }}\right)+v_{i, t, s}^{\text {nonuse }}+\epsilon_{i, t, s}^{\text {nonuse }}\right. \\
&>\left.\left\{\sum_{t=1}^{T} \max _{j}\left(v_{i, t, r \mid j}^{\text {use }}+v_{i, t, r \mid j}^{\text {other }}+\epsilon_{i, j, t, r}^{\text {use }}\right)+v_{i, t, r}^{\text {nonuse }}+\epsilon_{i, t, r}^{\text {nonuse }}\right\}_{\forall r \neq s}\right]
\end{aligned}
$$

where the modelled and non-modelled elements of nonuse utility can be taken out of the maximisation problem in the third equation since their magnitudes are, by definition, independent of the choice of recreation activity.

The nature of the probabilities in (13) and (14) are determined by the assumptions the analyst makes regarding the distribution of the error terms. For our purposes, we make specific structural assumptions that facilitate closed forms for both probability expressions.

Our first assumption, common to many analyses of discrete choices, is that that the useutility error components are independent draws from a Type I Extreme Value distribution with location parameter zero and scale parameter $\sigma^{R P}$ (i. e. $\left.\epsilon_{i, j, t, s}^{u s e} \sim \operatorname{IID} E V\left(0, \sigma^{R P}\right) \forall i, j, t, s\right)$. Here the $R P$ superscript reflects the fact that the scale of this error distribution will be revealed by the observed recreational behaviour data. Of course, the scale of utility is not determined from such data such that we apply the standard normalisation setting $\sigma^{R P}$ to a value of 1 . Under that assumption, (13) can be solved to give an expression for the probability of observing a particular recreational choice that takes the familiar multinomial logit (MNL) form;

$$
P_{i, j, t, 0}\left(\boldsymbol{\theta}_{\boldsymbol{i}}^{\text {use }}, \gamma_{i}\right)=\frac{e^{v_{i, t, 0 \mid j}^{u s e}+v_{i, t, 0 \mid j}^{\text {other }}}}{\sum_{k=0}^{J+1} e^{v_{i, t, 0 \mid k}^{u s e}+v_{i, t, 0 \mid k}^{\text {other }}}} \quad(\forall i, j, t)
$$

A somewhat more difficult econometric challenge is posed by the probability of SP choices 
(14). A first complexity arises in handling the expression $\max _{j}\left(v_{i, t, s \mid j}^{u s e}+v_{i, t, s \mid j}^{\text {other }}+\epsilon_{i, j, t, s}^{u s e}\right)$, which describes the use utility a respondent derives by solving the site-visitation problem and choosing which natural area to visit in time period $t$ under state of the world $s$. Notice that from the analyst's point of view the presence of the error component $\epsilon_{i, j, t, s}^{u s e}$ results in this maximum use utility being a random variate.

Of course, in a VCSE respondents choose between states of the world but do not provide details of that anticipated recreational behaviour. Accordingly, it is not possible to simply replace the maximisation expression with the utility of the particular site solving that maximisation problem. One way to proceed, follows from the observation that the set of arguments to the visitation problem are, by assumption, independent Type I Extreme Value variates with equal variance. It follows from properties of that distribution that an individual's maximum use utility in state of the world $s$ must also be an extreme value variate;

$$
\max _{j \in 1, \ldots, J+1} v_{i, t, s \mid j}^{u s e}+v_{i, t, s \mid j}^{o t h e r}+\epsilon_{i, j, t, s}^{u s e} \sim E V\left(\ln \sum_{j=1}^{J+1} e^{v_{i, t, s \mid j}^{u s e}+v_{i, t, s \mid j}^{o t h e r}}, 1\right) \quad(\forall i, t, s) .
$$

The distribution in (16) can equally be written as $\ln \sum_{j=1}^{J+1} e^{v_{i, t, s \mid j}^{u s e}+v_{i, t, s \mid j}^{o t h e r}}+\epsilon_{i, t, s}^{\max u s e}$, where $\epsilon_{i, t, s}^{\max u s e}$ is a standard Type I Extreme Value variate and the maximum use value from the set of sites is summarised in the form of a so called logexpsum term. Accordingly, our specification allows us to write the utility enjoyed by individual $i$ in period $t$ in state of the world $s$ as;

$$
u_{i, t, s}=\ln \sum_{j=1}^{J+1} e^{v_{i, t, s \mid j}^{u s e}+v_{i, t, s \mid j}^{\text {other }}}+\epsilon_{i, t, s}^{\max } \text { use }+v_{i, t, s}^{\text {nonuse }}+\epsilon_{i, t, s}^{\text {nonuse }} \quad(\forall i, t, s)
$$

where, as a consequence of (16), the error term $\epsilon_{i, t, s}^{\max u s e}$ is a standard Type I EV variate.

To proceed we need to make assumptions regarding the nonuse-utility error components, $\epsilon_{i, t, s}^{\text {nonuse }}$. First we assume these to be independent of $\epsilon_{i, t, s}^{\max u s e}$. Second we assume these are independent draws from a distribution in the family of conjugate distributions to the extreme value. Following Cardell, $(1997)$ we denote this distribution as $C\left(1 / \sigma_{S}^{S P}, 1\right)$. It follows that the distribution of the compound error $\epsilon_{i, t, s}^{\max } u s e+\epsilon_{i, t, s}^{\text {nonuse }}$ is itself distributed as a Type1 Extreme Value variate with mean zero and scale $\sigma_{S}^{S P}$. Since we have no reason to suspect that the error 
scales differ across scenarios, we impose the normalisation $\sigma_{s}^{S P}=\sigma^{S P}$ for all $s=1,2, \ldots, S$. It follows that (17) can be rewritten as:

$$
u_{i, t, s}=\frac{1}{\sigma^{S P}} \ln \sum_{j=1}^{J+1} e^{v_{i, t, s \mid j}^{u s e}+v_{i, t, s \mid j}^{\text {other }}}+v_{i, t, s}^{\text {nonuse }} / \sigma^{S P}+\epsilon_{i, t, s} \quad(\forall i, t, s)
$$

where $\epsilon_{i, t, s}=\left(\epsilon_{i, t, s}^{\max u s e}+\epsilon_{i, t, s}^{\text {nonuse }}\right) / \sigma^{S P}$ is distributed as an IID standard Type I EV variate. ${ }^{9}$

Of course, the VSCE scenarios are framed as choices made over the duration of one year such that the final step in deriving the econometric specification for the utility derived from a particular choice experiment scenario is to sum over all periods;

$$
\begin{array}{rlrl}
u_{i, s} & =\sum_{t=1}^{T} \frac{1}{\sigma^{S P}} \ln \sum_{j=1}^{J+1} e^{\left(v_{i, t, s \mid j}^{u s e}+v_{i, t, s \mid j}^{o t h e r}\right)}+\sum_{t=1}^{T} v_{i, t, s}^{\text {non-use }} / \sigma^{S P}+\sum_{t=1}^{T} \epsilon_{i . t . s} \\
& =v_{i, s}+\sum_{t=1}^{T} \epsilon_{i, t, s} & (\forall i, s)
\end{array}
$$

In the VSCE we describe subsequently individuals are presented with a series of tasks, $m=1,2, \ldots, M$ each of which asks them to state a preference over two particular scenarios, $s$ and $r$, such that the choice set $\mathbb{S}_{m}$ has only two members. Accordingly, substituting (19) into (14) reveals the probability of observing individual $i$ choosing option $s$ in choice task $m$, to be;

$$
P_{i, s, m}\left(\boldsymbol{\theta}_{\boldsymbol{i}}^{\text {use }}, \boldsymbol{\theta}_{\boldsymbol{i}}^{\text {nonuse }}, \gamma_{i}, \sigma^{S P}\right)=\operatorname{Prob}\left[u_{i, s, m}>u_{i, r, m}\right]
$$

\footnotetext{
${ }^{9}$ An anonymous referee suggested that the expression in (18) might be arrived at through an alternative story. Following Rust (1987), that story assumes that individuals choosing in a VCSE do not yet know their $\epsilon_{i, j, t, s}^{u s e}$ 's for future trip options, but rather make their decision based on the expectation of utility from such trips. In that case (17) might be written with the Euler-Mascheroni constant replacing the random term $\epsilon_{i, t, s}^{\max }$ use . Assuming that $\epsilon_{i, t, s}^{\text {non-use }} \sim \operatorname{IID} E V\left(0, \sigma^{S P}\right)$ would give an expression equivalent to (18).
} 


$$
=\operatorname{Prob}\left[v_{i, s}-v_{i, r}>\sum_{t=1}^{T} \varepsilon_{i, t, m}\right] \quad\left(\forall i, m \text { and } s, r \in \mathbb{s}_{m}\right)
$$

where, from a property of the Type I Extreme Value distribution, $\varepsilon_{i, t, m} \sim \operatorname{Logistic}(0,1)$. Observe that in differencing the utilities across the two scenarios any additive elements that are constant across scenarios are removed. For that reason, the data provides no means of identifying the areaspecific nonuse utility elements $a_{i, j, t}$.

To evaluate the probability in (20) we use a result from George and Mudholkar (1983) that shows how, as a convolution of standard logistic variates, the distribution of $\sum_{t=1}^{T} \varepsilon_{i, t, m}$ can be very closely approximated according to;

$$
\sum_{t=1}^{T} \varepsilon_{i, t, m} \sim t_{5 T+4}\left(0, \pi\left(\frac{15 T+12}{5 T^{2}+2 T}\right)^{-\frac{1}{2}}\right) \quad(\forall i, m)
$$

where $t_{5 T+4}(\cdot)$ is Student's $t$ distribution with $5 T+4$ degrees of freedom.

To complete our econometric specification, we note that our independence assumptions allow us to write the likelihood of observing individual $i$ 's recreational visit and SP choices as;

$$
L_{i}\left(\boldsymbol{\theta}_{i}\right)=\prod_{t} \prod_{j} P_{i, j, t}\left(\boldsymbol{\theta}_{i}^{u s e}, \gamma_{i}\right)^{Y_{i, j, t}} \prod_{m} \prod_{s \in \mathbb{S}_{m}} P_{i, s, m}\left(\boldsymbol{\theta}_{i}^{u s e}, \boldsymbol{\theta}_{i}^{\text {nonuse }}, \gamma_{i}\right)^{Y_{i, s, m}}
$$

Where $\boldsymbol{\theta}_{i}=\left[\begin{array}{llll}\boldsymbol{\theta}_{i}^{\text {use }} & \boldsymbol{\theta}_{i}^{\text {non-use }} & \gamma_{i} & \sigma^{S P}\end{array}\right]$ is a vector gathering together all the parameters of the behavioural model. $Y_{i, j, t}$ records visit choices such that $Y_{i, j, t}=1$ if individual $i$ chose to visit site $j$ in choice period $t$ and $Y_{i, j, t}=0$ otherwise. And, $Y_{i, s, m}$ records SP choices where $Y_{i, s, m}=1$ if individual $i$ chose $s$ from the set of scenarios presented to them in choice task $m$ and $Y_{i, s, m}=0$ otherwise.

Since our data are not sufficiently rich to allow estimation of a parameter vector $\left(\boldsymbol{\theta}_{i}\right)$ for each respondent, in our empirical application we adopt a random parameters specification (Revelt and Train, 1998; Train, 1998). Accordingly, we assume that each respondent's preference parameters are drawn from the population distribution of preference parameters, $f(\boldsymbol{\theta} \mid \boldsymbol{\Omega})$ which 
is specified up to some unknown set of parameters $\Omega$ which must also be estimated from the data. As detailed in Section 7, to maintain tractability we further assume that certain of the preference parameter distributions are degenerate constraining those parameters to be equal across all individuals.

The log likelihood for estimation is given by:

$$
\ln L(\boldsymbol{\theta}, \boldsymbol{\Omega})=\sum_{i=1}^{N} \ln \int L_{i}(\boldsymbol{\theta}) f(\boldsymbol{\theta} \mid \boldsymbol{\Omega}) d \boldsymbol{\theta}
$$

Optimising (23) over the parameters of the model provides maximum likelihood estimates of both use and nonuse parameters of the preference function.

\section{Monte Carlo Analysis}

Use-utility parameters can, of course, be estimated directly from RP data using (15). By combining RP data with SP data, the proposed estimation strategy offers two possible benefits; (i) improved information from which to identify use-utility parameters and (ii) additional information from which to identify nonuse-utility parameters. A key remaining question concerns the circumstances under which those informational benefits are likely to be realised.

To address that question, we undertake a Monte Carlo analysis that mimics features of the real-world application we analyse subsequently. Our Monte Carlo environment comprises a randomly located sample of 500 individuals who enjoy utility flows from three rivers that traverse a hypothetical landscape. The level of utility flow from a river location to an individual is determined by its proximity and the ecological status of the river at that location, the latter ranging on a four-point quality scale; bad, poor, good or excellent. Moreover, for simplicity, we assume simulated individuals hold identical preference parameters (that is; $\boldsymbol{\beta}_{i}=\boldsymbol{\beta}, \boldsymbol{b}_{i}=\boldsymbol{b}, \gamma_{i}=$ $\gamma, \lambda_{i}=\lambda, \forall i$ ), such that the utility function used in the Monte Carlo analysis is given by;

$$
\begin{gathered}
u_{i, t, s \mid j}=\boldsymbol{q}_{j, s} \boldsymbol{\beta}+\sum_{k=1}^{J} d_{i, k}^{\lambda} \boldsymbol{q}_{k, s} \boldsymbol{b}+\gamma\left(y_{i}-p_{k, i}-c_{s}\right)+\varepsilon_{i, j, t, s} \quad(j=1, \ldots, J \text { and } \forall i, t, s) \\
u_{i, t, s \mid J+1}=\alpha_{J+1}+\sum_{k=1}^{J} d_{i, k}^{\lambda} \boldsymbol{q}_{k, s} \boldsymbol{b}+\gamma\left(y_{i}-c_{s}\right)+\varepsilon_{i, J+1, t, s} \quad(\forall i, t, s)
\end{gathered}
$$


where $\varepsilon_{i, j, t, s}$ are independent draws of a standard Type 1 Extreme Value variate.

In this hypothetical world individuals enjoy a flow of nonuse utility from river locations while also gaining use utility from recreational trips taken to those river locations. For each Monte Carlo iteration we construct a simulated RP dataset recording patterns of trip-taking activity for each individual over a year and a simulated SP dataset detailing their responses to a VSCE exercise consisting of 12 choice tasks. Full details of the Monte Carlo design are provided in the Appendix.

Our first experiment explores the contribution that SP data from a VSCE can make to the identification of use-utility parameters. As motivation, consider the situation where an analyst wishes to use a VSCE in order to identify values associated with environmental qualities beyond the range observed in the current state of the world. The primary concern here is that without supporting RP data, information from the VSCE becomes the only source of identification for useutility parameters associated with these extended quality levels. In our Monte Carlo environment, we generate a current state of the world in which river quality is limited to the bad, poor and good categories. As such, the RP data provides no information regarding how greatly individuals value excellent water quality for recreational use. In contrast, the VSCE includes hypothetical scenarios in which river stretches are ascribed excellent quality. Our Monte Carlo experiment examines the degree to which the proposed estimator can use preferences revealed in the VSCE exercise to tease out the implied value placed on excellent water quality both in nonuse but also use.

To understand better the conditions under which the estimator may struggle in identifying use-utility parameters from SP data, recall from (18) that the contribution of use to the utility of a scenario $(s)$ presented as a VSCE choice option is captured by the so-called logsumexp term; $\ln \left(\sum_{j=1}^{J} e^{\left(v_{i, t, s \mid j}^{u s e}+v_{i, t, S \mid j}^{\text {other }}\right)}+e^{\left(\alpha_{J+1}+v_{i, t \mid j+1}^{\text {other }}\right)}\right)$. This term comprises two elements. The first element includes the $v_{i, t, s \mid j}^{u s e}$ terms which contain the use-utility parameters relating to the qualities of the $J$ recreational sites. The second element, captures the use utility of the outside good, $J+1$. Since this latter element remains constant, differences in the magnitude of the logsumexp term across VSCE choice options result solely from how they differ in the qualities of sites. Notice that the two elements of the logsumexp term are summed in a log operation. Accordingly, the same quality differences across two options in a VSCE choice task delivers a bigger difference in the logsumexp terms of those options when the use-utility of the outside good 
is small compared to when it is large. Since our ability to recover use-utility parameters of quality from VSCE data depends on the size of the signal provide by differences in the logsumexp term relative to the noise created by the error term (see (20)), it follows that identification will become increasingly difficult the greater the use-utility associated with the outside good.

The key findings of our first Monte Carlo experiment are summarised in Figure 2, with the detailed outcomes reported in the Appendix. Figure 2 plots out the distribution of parameter estimates from 500 iterations of the Monte Carlo experiment. The distributions in the left hand panel relate to the use-utility parameter for good water quality with true value 0.3 , while those in the right hand panel relate to the use-utility parameter for excellent water quality with true value 0.5. In both graphs, distributions are plotted from experiments run with different values of $\alpha_{J+1}$, the outside good utility parameter; specifically values of 3,5 , and 7 .

\section{[INSERT FIGURE 1 AROUND HERE]}

Recall that the use-utility parameter for good water quality is identified from both RP and SP data and we see that all three parameter distributions are centred on the true parameter. Moreover, in line with expectations, the tightest distribution of parameter estimates is observed when use utility for the outside good is small (s.d. 0.050) and the most dispersed when use utility for the outside good is large (s.d. 0.088). In contrast, excellent water quality is not observed in the current state of the world such that the use-utility parameter for that water quality is identified only from choices made in the VSCE. Again the pattern of results follows our expectations. At a relatively small value for the use-utility of the outside good, the distribution of the parameter estimates is centred on its true value with a reasonably tight dispersion (s.d. 0.128). Importantly, the Monte Carlo experiment confirms that the proposed estimation strategy using VSCE data to supplement RP data allows for estimation of use-utility parameters from qualities outside the range of current experience. As the magnitude of use-utility for the outside good increases to the medium value, however, the estimator encounters increasing difficulty tying down the value of the parameter (s.d. 3.126). Indeed, at the large value for use-utility of the outside good, the information provided by the VSCE data is so limited that the parameter is all but unidentified.

Our second key concern with the combined-data estimation strategy concerns the model's ability to return estimates of nonuse utility parameters. Put crudely, the estimation strategy for disentangling nonuse values is to observe the degree to which choices in the VSCE differ from the 
choices that would be expected if determined solely by use value. Of course, the degree to which choices will be influenced by nonuse considerations will depend on the relative size of the nonuse component of utility to the use component of utility. If the nonuse component is relatively large, then the SP data from the VSCE should provide good identification of the nonuse parameters. In contrast, if the nonuse component is relatively small, then identification may be difficult.

Three different sets of parameters were chosen for the Monte Carlo analysis which differed only in the size of the preference parameters determining the nonuse value derived from water qualities. To determine the size of those parameters we selected one scenario at random and evaluated the average gain in welfare that would be realised by the simulated individuals if all rivers were improved up to the excellent water quality level. ${ }^{10}$ As shown in Table I, we chose values for the nonuse parameters that resulted in the nonuse element of this average welfare gain being twice as large as the use element ("Large"), roughly equal to the use element ("Equal") and half the size of the use element ("Small").

\section{[INSERT TABLE I ABOUT HERE]}

Again full details of the Monte Carlo experiment are provided in the Appendix while here Figure 3 provides a summary of the findings for two quantities of interest. First, the left hand panel plots out the distribution of the distance-decay parameter for nonuse utility $(\lambda)$ estimated when nonuse utility is 'Large', 'Equal' and 'Small'. In all three cases those distributions are centred on the true parameter value of -1 . At the same time, as the relative size of the nonuse utility element declines the precision with which the distance-decay parameter is estimated also declines. A more detailed examination of the data shows that in the 'Equal' and 'Small' treatments a number of estimates of the distance decay parameter take on large negative values indicating that the estimator has difficulties identifying nonuse parameters for some realisations of the data. In those cases, we can assume that the nonuse elements of utility make little difference to the choices made in the VSCE. Accordingly, the estimator tends towards a distance-decay parameter that, in effect, discounts nonuse utility to zero.

\section{[INSERT FIGURE 2 AROUND HERE]}

\footnotetext{
10 The randomly chosen scenario had 2 river lengths of excellent quality, four of good quality, three of poor quality but no bad quality river lengths.
} 
The right hand panel of Figure 3 shows the distributions of estimates of the average welfare gain realised by the sample from improving all rivers to excellent water quality from the levels exhibited in the baseline scenario. Observe that in all three cases the simulations are centred on their true values with a similar level of precision being realised in all three treatments ('Large' s.d. 10.48; 'Medium' s.d. 12.64; 'Small' s.d. 10.11). It appears that the same decline in precision observed for the nonuse-utility parameters does not translate into declining precision of welfare estimates. That observation is being driven by the balancing of two effects; a decline in the precision of estimation of welfare from nonuse being paralleled by that nonuse welfare constituting an increasingly small element of overall welfare.

Now imagine that rather than the structural model combining RP and SP, an analyst had decided to use an approach that employed only the data from a VSCE. To maintain relative comparability, suppose that the approach adopted was to estimate a utility function that assumed the value derived from a choice experiment scenario could be approximated as the weighted sum of river qualities across the $M$ river stretches in that scenario according to;

$$
u_{i, t, s}=\sum_{m=1}^{M}\left(d_{i, m}+1\right)^{\lambda_{0}} \boldsymbol{q}_{m, s} \boldsymbol{b}_{\mathbf{0}}+\gamma_{0}\left(I_{i}-p_{s} / T\right)+\varepsilon_{i, j, t, s} \quad(\forall i, t, s)
$$

Notice that (25) is simply our specification of the nonuse elements of the utility function. In applying (25) to data in which choices are made according to both use and nonuse considerations, however, we might expect the water quality parameters, $\boldsymbol{b}_{\mathbf{0}}$, to pick up the combined effect of water quality on both use and nonuse. Likewise, the distance-decay parameter, $\lambda_{0}$, will pick up not only the effect of distance on nonuse utility but also the effect of travel costs on use utility. The question we wish to answer is whether (25) provides a sufficiently close approximation to the full structural model that the added complexity of estimating the full structural model might be considered an unnecessary luxury. Table II summarizes a third Monte Carlo experiment used to explore that question.

\section{[INSERT TABLE II ABOUT HERE]}

The Monte Carlo analyses reported in Table II use exactly the same simulations as those underpinning Figure 3. Observe that for all three treatments, the parameters on the quality 
variables and the distance decay show the bias that would be expected if the parameters were picking up elements relating to use utility as well as to nonuse utility. More importantly observe that the welfare estimates shown in the final row of Table II are systematically biased upwards with the size of bias in terms of standard deviations from the true value increasing from 1.31 for the 'Large' treatment, to 1.89 for the 'Equal' treatment, to 2.29 for the 'Small' treatment. We conclude that relying on a reduced-form approximation may result in significant errors in the calculation of welfare effects. Our Monte Carlo analysis lends support to the idea that econometric models should be carefully constructed to reflect the underlying structure of preferences.

\section{Empirical Case Study}

The data motiving this research arose from a valuation exercise carried out in northern England in 2008 examining the benefits of improving the ecological status of rivers. As shown in Figure 4: Study area and location of residence of sampleFigure 4, the study focused on a 70km square region mostly contained within the county of Yorkshire and traversed by three major rivers, the Aire, the Wharfe and the Calder.

\section{[INSERT FIGURE 4 AROUND HERE]}

Randomly sampling respondents from the study area to complete the valuation survey would have resulted in a dataset that was dominated by households from the Bradford-Leeds conurbation that sits at the heart of the region. A fundamental requirement for this research, however, was to ensure a sample that exhibited diversity with regards to spatial proximity to rivers of different qualities. To achieve that objective, surveying locations were chosen that evenly sampled the spatial extent of the study area (see Figure 4). Between 40 and 100 at-home interviews were conducted in each sampling location giving a total sample size of 1,805.

The survey instrument collected data on household socioeconomics, details of recreational use of river sites and asked respondents to complete a VSCE exercise focused on river water quality. Of the 1,805 households interviewed, some surveys were incomplete or lacked crucial information, such that the final dataset consisted of the recreational activity for 1,794 households with 1,708 of those also providing a complete set of responses to the VSCE.

Respondents were chosen as the adult in the household with responsibility for paying the household water bill. Identifying that individual as the Household Representative Person (HRP) 
allowed the analysis shown in Table III in which the sample's socioeconomic characteristics are compared to those recorded for the broader Yorkshire region in the 2011 census.

\section{[INSERT TABLE III AROUND HERE]}

Given the sampling strategy, it is not surprising that the sample over-represents suburban areas. Likewise retired households are more prevalent in the sample than the wider region, while full-time employed and small households are less prevalent. The final columns of Table III provide statistical confirmation that the sample is not representative of the region. As a consequence, a raking procedure was used to calculate sampling weights that matched the sample distribution of socioeconomic characteristics to their population equivalents. Using those weights in the subsequent regression analyses ensures valid inference with regards to the regional population.

The survey was explicitly designed to capture large quantities of spatially explicit data from respondents through a custom-built computer aided personal interview (CAPI). During the interview, respondents were shown an interactive map indicating the respondent's home location and the surrounding rivers within an area the same size as the full survey area.

The first section of the survey collected data for application of the travel cost method. First, respondents indicated on the map the river locations that they had visited for recreation over the course of the last 12 months and recorded how many times they had visited each of those sites. Details of the total number of all outdoor recreation trips taken in the last 12 months was also collected. Amongst respondents in the sample 18\% made no recreational trips to a river site in the previous year, $27 \%$ made 1 to 5 trips to a river site, $12 \%$ made 6 to 10 trips, with the remaining 33\% making more than 10 trips a year. The distribution of those trips across the study area is shown in Figure 5.

\section{[INSERT FIGURE 5 AROUND HERE]}

Respondents to the survey were asked to consider the level of river water quality that they experienced at recreational sites and introduced to a categorisation of water quality focused on the ecological status of rivers. The categorisation was developed with hydrological and ecological experts following the procedure described in Hime et al. (2009) and identified four levels of quality that moved from bad to poor to good to excellent with each level being associated with a quality colour; red, yellow, green and blue respectively. Each level was illustrated with an 
artist's impression of the typical appearance of the water, the river banks and bed, and the plant and animal species that might typically be associated with each ecological quality level. The illustrations also indicated the sorts of recreational activity that might be associated with each quality level, including wildlife watching, boating, swimming and coarse and game fishing.

In the second part of the survey, respondents participated in a VSCE. The VSCE concentrated on the main rivers in the study area; the Aire, the Wharfe and the Calder. To construct the choice experiment those rivers were divided into nine river lengths of equal extent. To construct a scenario to describe a future possible state of the world, each river length was ascribed a particular water quality and that quality illustrated on a map by colouring river lengths with their ascribed quality colour. Each scenario was associated with a cost motivated as an annual increase in the household water bills payable by each household in the Yorkshire region. Finally, a choice task was constructed by pairing two scenarios, as illustrated in Figure 1. Using a fractional factorial design, 60 choice tasks were constructed and divided into five blocks of 12 tasks. In the VSCE each respondent was presented with a particular block of VSCE question and, therefore, provided answers to 12 choice tasks

The recreational river sites available in the study region were identified using a GIS to find locations where the river could be accessed either by walking or driving and confirming those locations using aerial photographs. In total, 531 recreational sites were identified along the study rivers $(J=531)$. Information on the environmental characteristics of the recreational sites was identified in the GIS using Ordnance Survey's MasterMap and the Centre for Ecology and Hydrology's LandCover Map 2007. These provided details of the predominant land use around each of the recreational sites, which were grouped into four broad categories including woodland, farmland, grassland, and urban. The current water quality at each of the recreational sites was calculated from Environment Agency long-term water quality monitoring data and categorised on the four-point ecological status scale.

Of the 531 recreational sites, 286 had been visited by the sample of respondents (see Figure 5). Since some respondents visited a river site every day in the year, the recreational choice period was established as one day giving $T=365$. Travel costs to recreational sites $\left(t c_{i, j}\right)$ were calculated in the GIS with the cost of time valued at a third of the imputed household hourly after tax income. 
In order to evaluate nonuse utility the 9 river lengths defined for the purposes of the choice experiment were each further divided into 9 river stretches giving a total of 81 river stretches each of which was a little under $3 \mathrm{~km}$ in length. Nonuse utility was assumed to be derived from water quality across this set of 81 river stretches. ${ }^{11}$ Distance to each river stretch from each respondent's home $\left(d_{i, m}\right)$ was measured in the GIS

\section{Results}

Using the data collected from the study described in the previous section, we estimate three different models; (i) a simple travel cost model recovering estimates of use-utility parameters from just the RP data (ii) a mis-specified model capturing reduced-form parameters that combine use and nonuse utility estimated from just the SP data (as per our third Monte Carlo experiment) and (iii) the full structural model that combines RP and SP data to disentangle use and nonuse parameters.

In these models the qualities of river sites in the use-utility element, $\boldsymbol{q}_{j, s}$, consist of a set of dummy variables capturing ecological status (with bad status being the baseline), a set of dummy variables capturing the predominant land use at the site (with farmland being the baseline) and a variable measuring population density in the local area of the site. Likewise, our vector of qualities for the river stretches delivering nonuse utility, $\boldsymbol{q}_{m, s}$, consists only of a set of dummy variables indicating the ecological status of each stretch. All other features of rivers are assumed to stay constant across scenarios and hence difference out of the estimating equations.

In addition, our empirical application attempts to capture heterogeneity in preferences. To begin with we allow the utility of the no-trip option to be expressed as a constant $\alpha_{J+1}$ modified by a linear combination of socioeconomic regressors including HRP age and working status, household size, income, presence of children and a dummy for urban residence. For other elements, heterogeneity is allowed through adoption of a random parameters specification. In particular, we assume that the marginal utility of money parameter is drawn from a log normal distribution , $\gamma_{i} \sim L N\left(\gamma, \sigma_{\gamma}^{2}\right)$. Likewise we allow the distance-decay parameter and the utility of outdoor trips to non-river sites to be draws from normal distributions; specifically, $\lambda_{i} \sim N\left(\lambda, \sigma_{\lambda}^{2}\right)$

11 Notice that this differs slightly from the development in (11) of Section 4 where for notational convenience it was assumed that nonuse value was derived from the same set of sites as delivered use value. 
and $\alpha_{J+1, i} \sim N\left(\alpha_{J+1}, \sigma_{\alpha_{J+1}}^{2}\right)$. In contrast, we constrain the use and nonuse taste parameters for river quality to be constant across individuals; that is to say, $\boldsymbol{\beta}_{i}=\boldsymbol{\beta}(\forall i)$ and $\boldsymbol{b}_{i}=\boldsymbol{b}(\forall i)$. Finally, we constrain the parameters on the site-specific element of use utility to be constant across households but allow for unobserved differences in quality across sites, comparing two different model specifications. The first we describe as a random effects specification in which unobserved site-specific quality elements are modelled as draws from a normal distribution; $\alpha_{j, i, t}=$ $\alpha_{j} \sim N\left(\alpha, \sigma_{\alpha}^{2}\right)(\forall j, i, t)$. The second specification, ascribes each site to its geographically defined sub-basin (using the UK government's WFD classification of sub-basins) and includes a series of 24 dummy variables. We describe that as a fixed effects specification.

Since the models contain random parameters, we use simulated maximum likelihood to recover parameter estimates. Regression results for the various models are reported in Error!

\section{Reference source not found..}

\section{[INSERT TABLE IV ABOUT HERE]}

Focusing first on the parameter estimates from our full structural model using combined $\mathrm{RP}$ and SP data we observe that a comparison across fixed effects and random effects specifications shows the models to be qualitatively similar both in terms of parameter sign, magnitude and significance. The random effects estimator, however, dominates in terms of the log-likelihood for a substantially more parsimonious specification such that our discussion focuses particularly on findings from that specification. Within that model we find that the parameters are all plausibly signed and in the main statistically significant at the usual levels of confidence. Most importantly, given the focus of the study, we find that the parameters on ecological status progress in the expected order for both use and nonuse utility with excellent quality being preferred to good quality being preferred to poor quality being preferred to bad quality. In the case of use utility, however, only the excellent water quality parameter proves to be significant at the $95 \%$ confidence level.

Comparing the parameters on river quality for nonuse utility to those for use utility reveals the latter to be an order of magnitude larger. Of course, that might be expected given the two measure quite different quantities. In the case of use utility, the parameters measure the extra utility a household would realise if they were to experience that water quality (compared to the 
base case bad quality) when making a day visit to a river site. In the case of nonuse utility, the parameters measure the additional flow of nonuse utility over the baseline that a household would realise from a river stretch of that water quality located next to their home, each day of the year. Our subsequent welfare analysis provides insights as to how these differences in parameter magnitude translate into differences in annual flows of utility from use and nonuse.

The other parameter estimate worthy of closer scrutiny is the distance-decay parameter on nonuse utility. Error! Reference source not found. shows this to be significantly different from zero indicating that the nonuse utility a household enjoys from a river declines with the distance that river is from their home. Indeed, the parameter value of -1.18 suggests that the rate of decline to be somewhat greater than the inverse of distance. Indeed a river stretch at $10 \mathrm{~km}$ distance is valued at only $7 \%$ of the value of a river stretch at $1 \mathrm{~km}$ distance with that figure falling to $3 \%$ at a distance of $20 \mathrm{~km}$.

Considering next the travel cost model, we note again the similarity of the parameter estimates and use the same model fit and parsimony argument to justify focusing attention on the Random Effects specification. Comparing this travel cost model to the combined data model, observe from Error! Reference source not found. that the outside good utility and other recreation utility parameters are relatively large, a finding that our Monte Carlo analysis suggests will limit the contribution that the SP data can make to the estimation of use-utility parameters. Indeed, the estimated parameters support that contention; we observe that the use-utility parameters from the combined data model are mostly similar in sign and magnitude to the parameters estimated on the travel cost model. ${ }^{12}$ In other words, in this case study the majority of the work in identifying the use-utility parameters is being done by the RP data.

That observation carries over into a comparison of the combined data model with the misspecified model using just SP data where again we observe very similar parameter estimates for the nonuse taste parameters for river water quality. The mis-specification in the SP data model is, however, evident in the cost parameter and distance decay parameters. Compared to the combined data model we see that the mean of the distribution of the former to suggest a

${ }^{12}$ In addition, as per the Monte Carlo experiment reported in the Appendix, we attempted to estimate a hypothetical bias parameter capturing a possible tendency to overestimate the volume of use of river recreation sites in an SP exercise. In line with the Monte Carlo findings, the size of the outside good utility element meant that the hypothetical bias parameter could not be unidentified in this case. 
significantly larger marginal utility of money while the mean of the latter suggests a less significant rate of decay in utility with distance.

Taking the estimated parameters from the two random effects models and the SP data model, it is possible to carry out a welfare analysis exploring the average welfare gains that would be realised in our sample if all rivers in the region were improved from their current ecological status to excellent ecological status. The results of that analysis are presented in Table V where the standard errors of the welfare estimates have been estimated parametrically using the Krinsky-Robb resampling procedure.

\section{[INSERT TABLE V ABOUT HERE]}

From Table $\mathrm{V}$ we see that the combined data model suggests an annual welfare flow from the improvement in river water quality amounting to $£ 20.77$ (std. err. $£ 2.39$ ). That quantity can be further broken down into a flow derived in nonuse of $£ 17.79$ (std. err. $£ 2.38$ ) and a flow derived from use $£ 3.04$ (std. err. £0.97). Accordingly, our data suggest that the values of improvements in ecological status are gained mainly from nonuse utility which are 5.8 times larger than those gained from increases in use utility.

Comparing the welfare estimates from the combined model to that from the travel cost model shows that both return similar estimates of welfare gains reflecting our earlier observation that in this case study the use utility parameters are identified mainly from information in the RP data. In contrast to our MC analysis, we also find that the mis-specified model based on just SP data returns a welfare estimate that while being a little lower on average from that returned by the combined data model is statistically indistinguishable from the latter. Of course, given the large differences in the cost and distance decay parameters of the two models, there is no guarantee that that similarity would hold for welfare analyses using the two models applied to very different landscapes with different distributions of quality-differentiated natural areas.

\section{Concluding Remarks}

The central contribution of this paper is to build an econometric specification for the analysis of VSCE data that is derived from a coherent structural model of preferences for landscape-wide environmental quality change. The functional form of the econometric specification of the preference function describing choice behaviour in a VSCE is highly nonlinear 
which stands in stark contrast to standard practice in the field of choice modelling. Indeed, analysts have come to increasingly depend on linear specifications of preference functions that are amenable to estimation using the mixed logit model. Often that modelling choice is justified through appeal to the results of McFadden and Train (2000) who show that any RUM model can be approximated to any degree of accuracy by a mixed logit with appropriate choice of variables and mixing distribution. That reliance on linear preference functions has been questioned by (Andersen et al., 2012) and this paper lends weight to that criticism. In particular, our Monte Carlo analysis shows how a reduced form model (admittedly without random coefficients) fails to accurately predict welfare changes. Indeed, our research suggests that there may be good reasons to be suspicious of welfare calculations emanating from models using reduced-form specifications of the preference function especially when, as in the case studied in this paper, there is good reason to believe that the true preference function is highly non-linear.

In the context of our study, another important justification for basing our econometric specification on a structurally-coherent model of preferences results from our use of both RP and SP data in estimation. Evidently, any theoretically consistent attempt at joint estimation must clearly identify which parameters of the preference function are informed on by the two different data sources (Eom and Larson, 2006). In our case, the behavioural data reflect just on the parameters determining use value and the hypothetical choice data on those determining both use and nonuse value. Those differences fall naturally out of our derivation of the econometric models for the two different forms of data from the same structural description of preferences.

A final justification for the importance of structural modelling results from the requirement for benefits transfer. The use of reduced-form specifications that confound use and nonuse values or inadequately describes substitution relationships inhibit effective transfer of the value estimates outside the study area to locations exhibiting different spatial patterns of quality-differentiated substitutes.

With regards to the findings of the empirical exercise, a number of results stand out. First, while it has long been established that utility from the use of a natural resource declines with distance from an individual's home our research provides evidence to show that the same is true of utility from nonuse. Indeed, we find that nonuse values for the ecological quality of rivers decline at a rate approximately equal to the inverse of distance. Our research, therefore, supports 
the speculation of Bateman et al. (2006) that there may be a cultural identity or 'ownership' dimension to nonuse values that precipitates distance decay in those values. Those speculations were based on the empirical findings of distance decay in the expressions of value made by nonusers of a resource (Bateman et al., 2005; Hanley et al., 2003). As far as we are aware, our empirical findings are the first to identify distance decay in nonuse values themselves.

Our empirical application also reveals that value flows from river quality attributes differ in use and nonuse. Our empirical estimates suggest that nonuse utility may be a significant component of the welfare gains that arise from improving the ecological status of rivers. Accordingly, ignoring nonuse values may significantly understate the welfare gains that might arise from landscape-wide programmes of river quality improvement. 


\section{References}

Adamowicz, W., Louviere, J., Williams, M., 1994. Combining Revealed and Stated Preference Methods for Valuing Environmental Amenities. Journal of Environmental Economics and Management 26, 271-292.

Andersen, S., Harrison, G.W., Hole, A.R., Lau, M., Rutström, E.E., 2012. Non-linear mixed logit. Theory and Decision 73, 77-96.

Bateman, I.J., Cooper, P., Georgiou, S., Navrud, S., Poe, G.L., Ready, R.C., Riera, P., Ryan, M., Vossler, C.A., 2005. Economic valuation of policies for managing acidity in remote mountain lakes: Examining validity through scope sensitivity testing. Aquatic Sciences 67, 274-291.

Bateman, I.J., Day, B.H., Georgiou, S., Lake, I., 2006. The aggregation of environmental benefit values: Welfare measures, distance decay and total WTP. Ecological Economics 60, 450-460.

Birol, E., Karousakis, K., Koundouri, P., 2006. Using a choice experiment to account for preference heterogeneity in wetland attributes: The case of Cheimaditida wetland in Greece. Ecological Economics 60, 145-156.

Boxall, P.C., Adamowicz, W.L., Swait, J., Williams, M., Louviere, J., 1996. A comparison of stated preference methods for environmental valuation. Ecological Economics 18, 243-253.

Brouwer, R., Martin-Ortega, J., Berbel, J., 2010. Spatial preference heterogeneity: a choice experiment. Land Economics 86, 552-568.

Cameron, T.A., 1992. Combining Contingent Valuation and Travel Cost Data for the Valuation of Nonmarket Goods. Land Economics 68, 302-317.

Cardell, N.S., 1997. Variance components structures for the extreme-value and logistic distributions with application to models of heterogeneity. Econometric Theory, 13(2), pp.185213.

Caudill, S.B., Groothuis, P.A., Whitehead, J.C., 2011. The Development and Estimation of a Latent Choice Multinomial Logit Model with Application to Contingent Valuation. American Journal of Agricultural Economics 93, 983-992.

Christie, M., Hanley, N., Hynes, S., 2007. Valuing enhancements to forest recreation using choice experiment and contingent behaviour methods. Journal of Forest Economics 13, 75-102.

Concu, G.B., 2007. Investigating distance effects on environmental values: a choice modelling approach*. Australian Journal of Agricultural and Resource Economics 51, 175-194.

Cummings, R.G., Harrison, G.W., 1995. The measurement and decomposition of nonuse values: A critical review. Environmental and Resource Economics 5, 225-247.

Davis, R.K., Knetsch, J., 1966. Comparisons of Methods for Recreation Evaluation, in: Kneese, A., Smith, S. (Eds.), Water Research. Johns Hopkins University Press, Baltimore, MD.

De Valck, J., Broekx, S., Liekens, I., Aertsens, J., Vranken, L., 2017. Testing the Influence of Substitute Sites in Nature Valuation by Using Spatial Discounting Factors. Environmental and Resource Economics 66, 17-43.

Englin, J., Cameron, T.A., 1996. Augmenting travel cost models with contingent behavior data. 
Environmental and Resource Economics 7, 133-147.

Eom, Y.-S., Larson, D.M., 2006. Improving environmental valuation estimates through consistent use of revealed and stated preference information. Journal of Environmental Economics and Management 52, 501-516.

George, E., Mudholkar, G., 1983. On the convolution of logistic random variables. Metrika 30, 113.

Hanley, N., Schläpfer, F., Spurgeon, J., 2003. Aggregating the benefits of environmental improvements: distance-decay functions for use and nonuse values. Journal of Environmental Management 68, 297-304.

Hanley, N., Wright, R.E., Adamowicz, V., 1998. Using Choice Experiments to Value the Environment. Environmental and Resource Economics 11, 413-428.

Hime, S., Bateman, I.J., Posen, P., Hutchins, M., 2009. A transferable water quality ladder for conveying use and ecological information within public surveys. CSERGE working paper EDM.

Horne, P., Boxall, P.C., Adamowicz, W.L., 2005. Multiple-use management of forest recreation sites: a spatially explicit choice experiment. Forest Ecology and Management 207, 189-199.

Jørgensen, S.L., Olsen, S.B., Ladenburg, J., Martinsen, L., Svenningsen, S.R., Hasler, B., 2013. Spatially induced disparities in users' and nonusers' WTP for water quality improvementsTesting the effect of multiple substitutes and distance decay. Ecological Economics 92, 58-66.

Kataria, M., Bateman, I., Christensen, T., Dubgaard, A., Hasler, B., Hime, S., Ladenburg, J., Levin, G., Martinsen, L., Nissen, C., 2012. Scenario realism and welfare estimates in choice experiments - A non-market valuation study on the European water framework directive. Journal of Environmental Management 94, 25-33.

McFadden, D., 1973. Conditional Logit Analysis of Qualitative Choice Behavior, in: Zarembka, P. (Ed.), Frontiers of Econometrics. Academic Press, New York.

McFadden, D., Train, K., 2000. Mixed MNL models for discrete response. Journal of Applied Econometrics 15, 447-470.

Meyerhoff, J., Boeri, M., Hartje, V., 2014. The value of water quality improvements in the region Berlin-Brandenburg as a function of distance and state residency. Water Resources and Economics 5, 49-66.

Morey, E.R., Rowe, R.D., Watson, M., 1993. A Repeated Nested-Logit Model of Atlantic Salmon Fishing. American Journal of Agricultural Economics 75, 578-592.

Oster, S., 1977. Survey results on the benefits of water pollution abatement in the Merrimack River Basin. Water Resources Research 13, 882-884.

Pate, J., Loomis, J., 1997. The effect of distance on willingness to pay values: a case study of wetlands and salmon in California. Ecological Economics 20, 199-207.

Phaneuf, D.J., von Haefen, R.H., 2009. Chapter 12 Estimating the Demand for Quality with Discrete Choice Models, Quantifying Consumer Preferences. Emerald Group Publishing Limited, pp. 317347.

Revelt, D., Train, K., 1998. Mixed logit with repeated choices: households' choices of appliance 
efficiency level. Review of economics and statistics 80, 647-657.

Rust, J., 1987. Optimal replacement of GMC bus engines: An empirical model of Harold Zurcher. Econometrica, 55(5). 999-1033.

Schaafsma, M., Brouwer, R., 2013. Testing geographical framing and substitution effects in spatial choice experiments. Journal of Choice Modelling 8, 32-48.

Schaafsma, M., Brouwer, R., Rose, J., 2012. Directional heterogeneity in WTP models for environmental valuation. Ecological Economics 79, 21-31.

Söderberg, M., Barton, D.N., 2014. Marginal WTP and Distance Decay: The Role of 'Protest' and 'True Zero' Responses in the Economic Valuation of Recreational Water Quality. Environmental and Resource Economics 59, 389-405.

Stithou, M., Hynes, S., Hanley, N., Campbell, D., 2013. Estimating the Value of Achieving "Good Ecological Status" in the Boyne River Catchment in Ireland Using Choice Experiments. The Economic and Social Review; Vol 43, No 3, Autumn (2012).

Sutherland, R.J., Walsh, R.G., 1985. Effect of Distance on the Preservation Value of Water Quality. Land Economics 61, 281-291.

Taylor, T., Longo, A., 2010. Valuing algal bloom in the Black Sea Coast of Bulgaria: A choice experiments approach. Journal of Environmental Management 91, 1963-1971.

Timmins, C., Schlenker, W., 2009. Reduced-form versus structural modeling in environmental and resource economics. Annual Review of Resource Economics 1, 351-380.

Train, K.E., 1998. Recreation Demand Models with Taste Differences over People. Land Economics 74, 230-239.

Whitehead, J.C., Haab, T.C., Huang, J.-C., 2000. Measuring recreation benefits of quality improvements with revealed and stated behavior data. Resource and Energy Economics 22, 339354.

Whitehead, J.C., Pattanayak, S.K., Van Houtven, G.L., Gelso, B.R., 2008. Combining revealed and stated preference data to estimate the nonmarket value of ecological services: an assessment of the state of the science. Journal of Economic Surveys 22, 872-908.

Yao, R.T., Scarpa, R., Turner, J.A., Barnard, T.D., Rose, J.M., Palma, J.H.N., Harrison, D.R., 2014. Valuing biodiversity enhancement in New Zealand's planted forests: Socioeconomic and spatial determinants of willingness-to-pay. Ecological Economics 98, 90-101. 


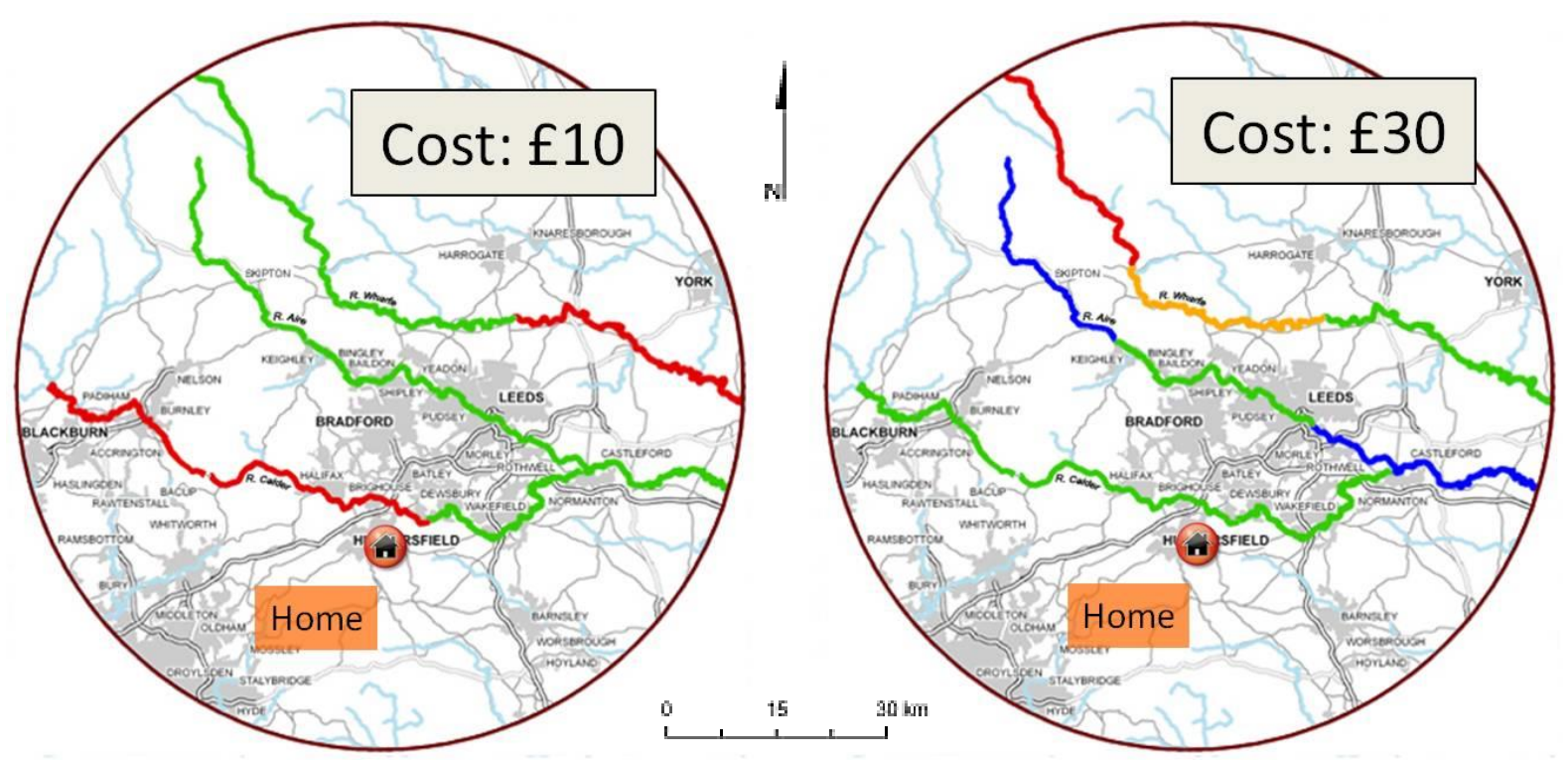

Figure 1: Typical Task from the Visual Spatial Choice Experiment
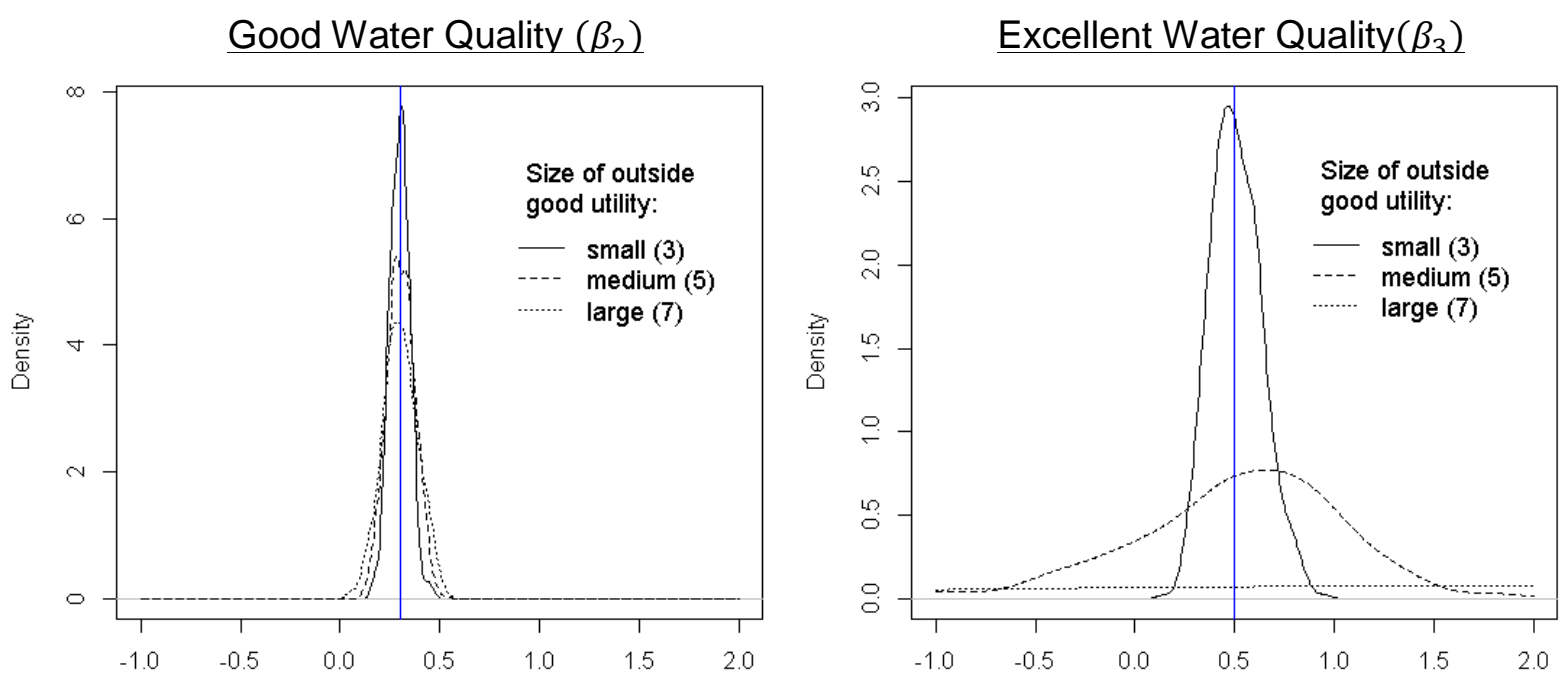

Figure 2: Distribution of use-utility water quality parameters from Monte Carlo experiments differing in the size of the outside good utility parameter $(\alpha)$ 

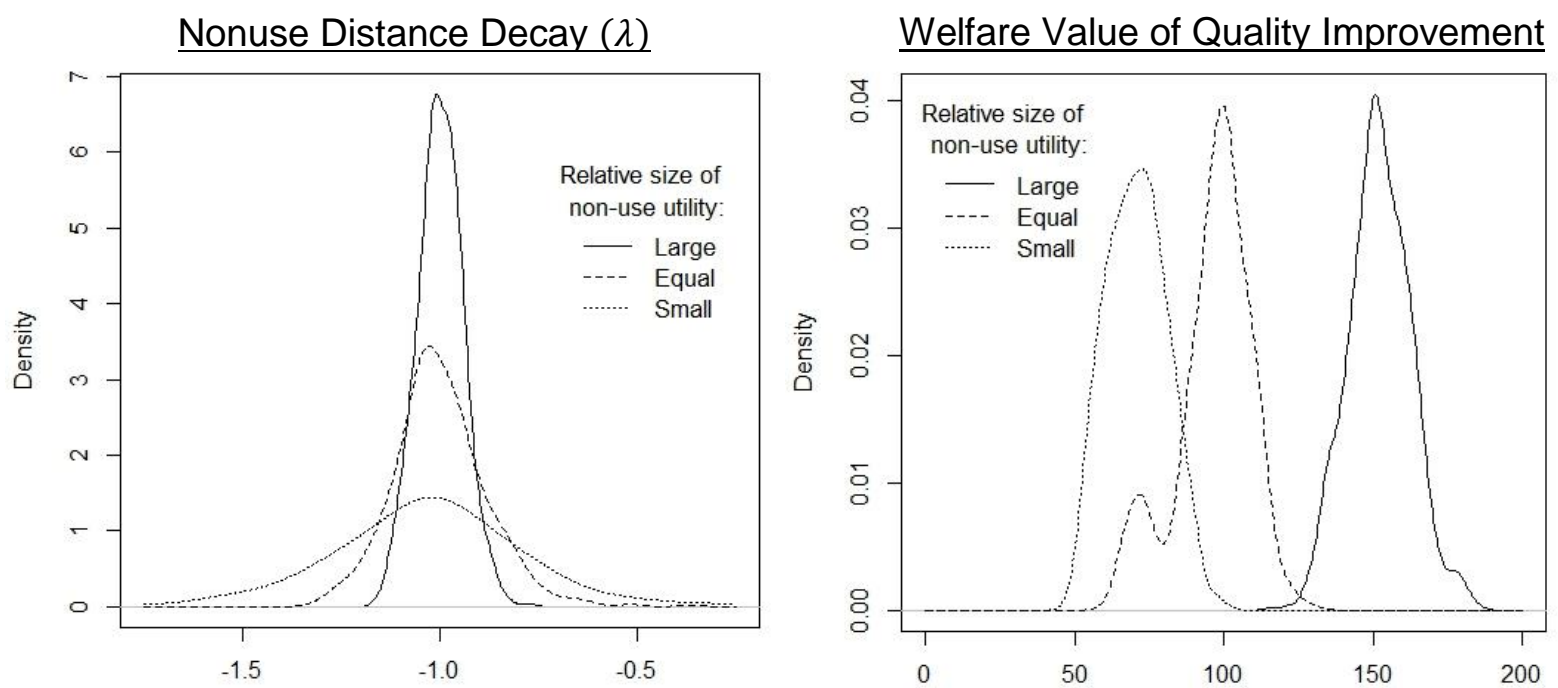

Figure 3: Distribution of nonuse-utility distance decay parameter and welfare estimates for improvement to excellent water quality from Monte Carlo experiments differing in the relative size of nonuse utility

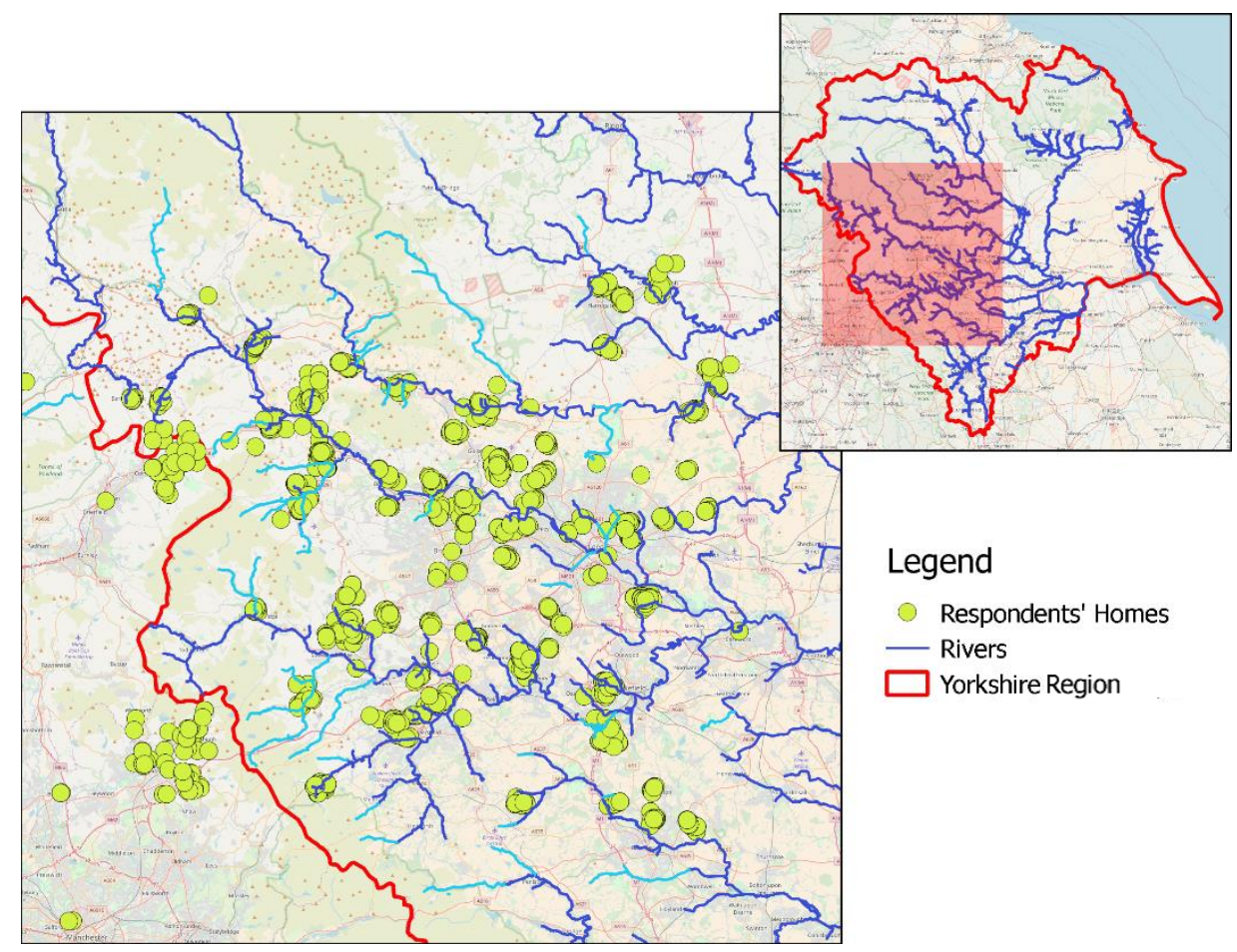

Figure 4: Study area and location of residence of sample 


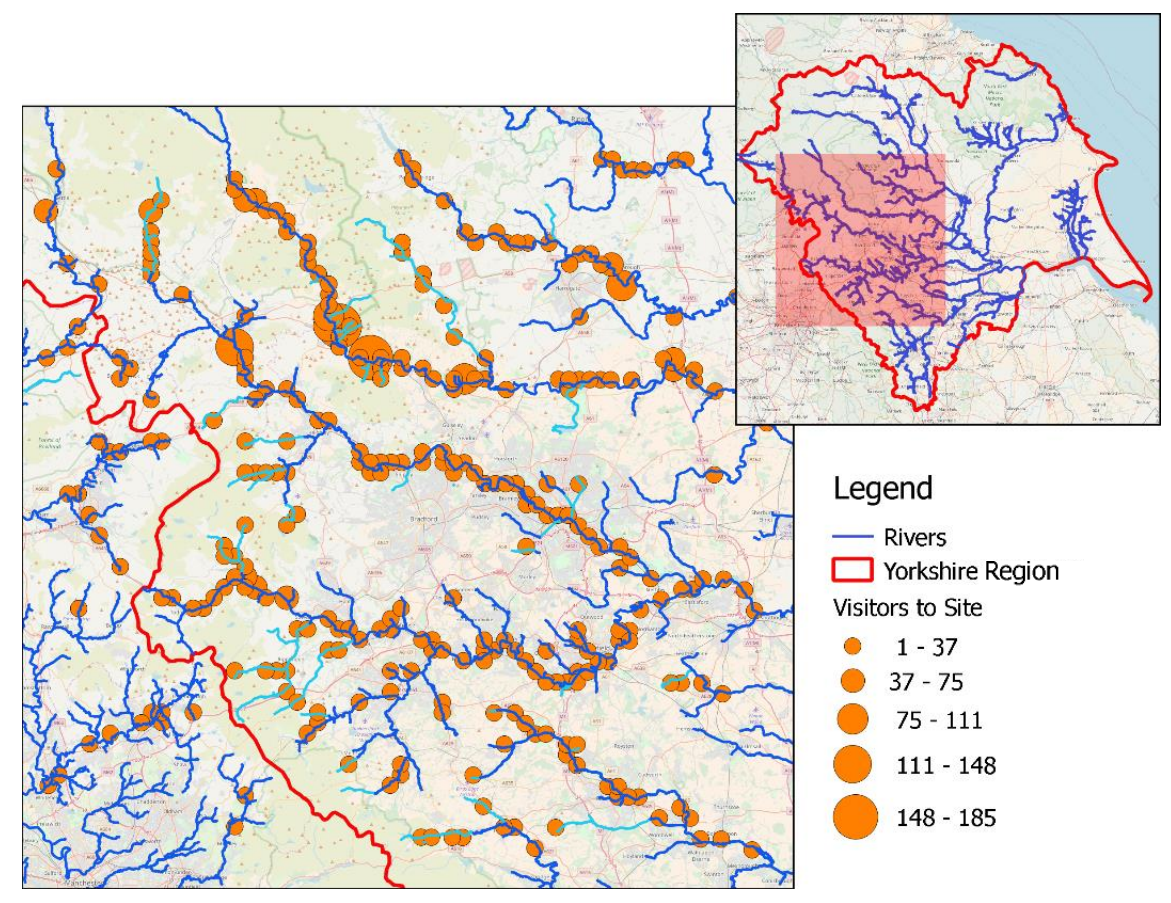

Figure 5: River sites visited by the sample 
Table I: Monte Carlo Simulation Treatments

\begin{tabular}{|c|c|c|c|c|c|c|}
\hline \multirow{2}{*}{$\begin{array}{l}\text { MC Simulation } \\
\text { Treatment } \\
\text { Name }\end{array}$} & \multicolumn{3}{|c|}{ Nonuse Parameters } & \multicolumn{3}{|c|}{$\begin{array}{c}\text { Average Welfare Change from } \\
\text { Improvement of all Rivers to } \\
\text { Excellent Quality }\end{array}$} \\
\hline & $\begin{array}{l}\text { Poor } \\
\text { Quality } \\
\left(b_{1}\right)\end{array}$ & $\begin{array}{l}\text { Good } \\
\text { Quality } \\
\left(b_{2}\right)\end{array}$ & $\begin{array}{l}\text { Excellent } \\
\text { Quality } \\
\quad\left(b_{3}\right)\end{array}$ & $\begin{array}{l}\text { Nonuse } \\
\text { Element }\end{array}$ & $\begin{array}{c}\text { Use } \\
\text { Element }\end{array}$ & $\begin{array}{l}\text { Ratio of Use } \\
\text { to Nonuse } \\
\text { Element }\end{array}$ \\
\hline Large & 2 & 6 & 10 & 104.3 & 46.9 & 2.22 \\
\hline Equal & 1 & 3 & 5 & 52.1 & 46.9 & 1.11 \\
\hline Small & .5 & 1.5 & 2.5 & 26.1 & 46.9 & 0.56 \\
\hline
\end{tabular}

Table II: Summary of Monte Carlo simulations for mis-specified model applied to stated preference data

\begin{tabular}{|c|c|c|c|c|c|c|}
\hline \multirow[b]{2}{*}{ Parameters } & \multicolumn{2}{|c|}{ Nonuse: Large } & \multicolumn{2}{|c|}{ Nonuse: Equal } & \multicolumn{2}{|c|}{ Nonuse: Small } \\
\hline & True & $\begin{array}{c}\text { Mean } \\
\text { (sd) }\end{array}$ & True & $\begin{array}{c}\text { Mean } \\
\text { (sd) }\end{array}$ & True & $\begin{array}{c}\text { Mean } \\
\text { (sd) }\end{array}$ \\
\hline $\operatorname{Cost}(\gamma)$ & -0.1 & $\begin{array}{l}-0.101 \\
(0.006)\end{array}$ & -0.1 & $\begin{array}{l}-0.102 \\
(0.006)\end{array}$ & -0.1 & $\begin{array}{r}-0.1023 \\
(0.006)\end{array}$ \\
\hline Poor Quality $\left(b_{1}\right)$ & 2 & $\begin{array}{r}4.953 \\
(0.785)\end{array}$ & 1 & $\begin{array}{c}3.541 \\
(0.763)\end{array}$ & 0.5 & $\begin{array}{c}2.809 \\
(0,736)\end{array}$ \\
\hline Good Quality $\left(b_{2}\right)$ & 6 & $\begin{array}{l}15.152 \\
(1.337)\end{array}$ & 3 & $\begin{array}{l}11.049 \\
(1.175)\end{array}$ & 1.5 & $\begin{array}{c}8.941 \\
(1.037)\end{array}$ \\
\hline Excellent Quality $\left(b_{3}\right)$ & 10 & $\begin{array}{l}26.435 \\
(2.131)\end{array}$ & 5 & $\begin{array}{l}19.666 \\
(1.791)\end{array}$ & 2.5 & $\begin{array}{l}16.211 \\
(1.572)\end{array}$ \\
\hline Distance Decay $(\lambda)$ & -1 & $\begin{array}{l}-1.169 \\
(0.028)\end{array}$ & -1 & $\begin{array}{l}-1.195 \\
(0.033)\end{array}$ & -1 & $\begin{array}{r}-1.214 \\
(0.037)\end{array}$ \\
\hline Welfare & 151.22 & $\begin{array}{l}166.08 \\
(11.35)\end{array}$ & 99.08 & $\begin{array}{l}115.38 \\
(8.623)\end{array}$ & 72.99 & $\begin{array}{c}90.30 \\
(7.538)\end{array}$ \\
\hline
\end{tabular}


Table III: Comparison of Sample and Population Characteristics

\begin{tabular}{|c|c|c|c|c|}
\hline Characteristics & $\begin{array}{l}\text { Yorkshire } \\
\text { Region }\end{array}$ & Sample & $\begin{array}{c}\text { Pearson } \\
\text { stat }\end{array}$ & $p$-value \\
\hline \multicolumn{5}{|l|}{ Age of HRP } \\
\hline$<35$ & $18.4 \%$ & $23.4 \%$ & & \\
\hline 35 to 54 & $38.4 \%$ & $32.1 \%$ & & \\
\hline 55 to 64 & $17.0 \%$ & $17.5 \%$ & & \\
\hline$>65$ & $26.3 \%$ & $27.0 \%$ & 43.91 & $<0.001^{* * *}$ \\
\hline \multicolumn{5}{|l|}{ Household Size } \\
\hline Small (1 or 2 ) & $65.7 \%$ & $57.7 \%$ & & \\
\hline Medium (3 to 5) & $31.9 \%$ & $38.5 \%$ & & \\
\hline $\operatorname{Big}(>5)$ & $2.4 \%$ & $3.8 \%$ & 56.81 & $<0.001^{* * *}$ \\
\hline \multicolumn{5}{|l|}{ Children } \\
\hline Yes & $28.7 \%$ & $35.5 \%$ & & \\
\hline No & $71.3 \%$ & $64.5 \%$ & 40.98 & $<0.001^{* * *}$ \\
\hline \multicolumn{5}{|l|}{ Employment of HRP } \\
\hline Part time & $9.3 \%$ & $13.5 \%$ & & \\
\hline Full time & $41.7 \%$ & $25.6 \%$ & & \\
\hline Self employed & $10.1 \%$ & $7.6 \%$ & & \\
\hline Unemployed & $3.5 \%$ & $3.6 \%$ & & \\
\hline Student & $2.0 \%$ & $3.7 \%$ & & \\
\hline Retired & $26.2 \%$ & $33.2 \%$ & & \\
\hline Looking after Home & $1.8 \%$ & $8.5 \%$ & & \\
\hline Other & $1.5 \%$ & $0.6 \%$ & & \\
\hline Sick & $3.9 \%$ & $3.6 \%$ & 693.59 & $<0.001^{* * *}$ \\
\hline \multicolumn{5}{|l|}{ Residence } \\
\hline Metropolitan & $54.1 \%$ & $58.5 \%$ & & \\
\hline Town & $29.7 \%$ & $22.0 \%$ & & \\
\hline Suburb & $10.1 \%$ & $16.6 \%$ & & \\
\hline Rural & $6.1 \%$ & $3.0 \%$ & 144.63 & $<0.001^{* * *}$ \\
\hline Total Households & $2,186,513$ & 1,794 & & \\
\hline
\end{tabular}

Notes: Statistics report the probability that the sample could have been drawn at random from the Yorkshire region population. 


\begin{tabular}{|c|c|c|c|c|c|}
\hline \multirow{3}{*}{ Parameter } & \multicolumn{5}{|c|}{ Parameter Estimates (std.err.) } \\
\hline & \multicolumn{2}{|c|}{$\begin{array}{c}\text { Combined Data } \\
\text { Model }\end{array}$} & \multicolumn{2}{|c|}{$\begin{array}{c}\text { Revealed Preference } \\
\text { Model }\end{array}$} & \multirow{2}{*}{$\begin{array}{c}\text { Stated } \\
\text { Preference } \\
\text { Model }\end{array}$} \\
\hline & $\begin{array}{l}\text { Random } \\
\text { Effects }\end{array}$ & $\begin{array}{c}\text { Fixed } \\
\text { Effects }\end{array}$ & $\begin{array}{l}\text { Random } \\
\text { Effects }\end{array}$ & $\begin{array}{c}\text { Fixed } \\
\text { Effects }^{\dagger}\end{array}$ & \\
\hline
\end{tabular}

Use \& Nonuse Utility Parameters

$$
\begin{aligned}
& \operatorname{Cost}\left(\gamma_{i} \sim L N\left(\gamma, \sigma_{\gamma}^{2}\right)\right) \\
& \text { - Location of Distribution }(\gamma) \\
& \text { - Scale of Distribution }\left(\sigma_{\gamma}\right)
\end{aligned}
$$

$\begin{array}{ccccc}-1.398^{* * *} & -0.983^{* * *} & -1.410^{* * *} & -1.033^{* * *} & -0.255^{* * *} \\ (0.074) & (0.076) & (0.081) & (0.083) & (0.062) \\ 1.433^{* * *} & 1.586^{* * *} & 1.485^{* * *} & 1.534^{* * *} & 2.054^{* * *} \\ (0.075) & (0.082) & (0.071) & (0.094) & (0.058)\end{array}$

Use Utility Parameters

Recreational Trip Type:

No Trip $\left(\alpha_{J+1}\right)$
- Constant
- Age
- Hge Squared
- Children
- In(Income)
- Urban residence
- Working (base case)
- Employed
- Retired
Other Trip $\left(\alpha_{J+2, i} \sim N\left(\alpha_{J+2}, \sigma_{\alpha_{J+2}}^{2}\right)\right)$
- Location of Distribution $\left(\alpha_{J+2}\right)$
Scale of Distribution $\left(\sigma_{\alpha_{J+2}}\right)$

$\begin{array}{cccc}5.445^{* * *} & 4.219^{* * *} & 6.587^{* * *} & 4.204^{* *} \\ (0.461) & (0.829) & (0.575) & (1.851) \\ -0.003 & 0.028 & -0.019 & 0.025 \\ (0.012) & (0.025) & (0.015) & (0.037) \\ 0.325^{* * *} & 0.041 & 0.412^{* *} & 0.095 \\ (0.124) & (0.278) & (0.169) & (0.434) \\ 0.039^{* * *} & 0.049^{* * *} & -0.029^{* * *} & 0.041^{* * *} \\ (0.003) & (0.004) & (0.004) & (0.010) \\ 0.713^{* * *} & 0.637^{* * *} & 0.667^{* * *} & 0.593^{* * *} \\ (0.047) & (0.074) & (0.042) & (0.071) \\ 0.072 & 0.309^{*} & 0.034 & 0.326 \\ (0.111) & (0.173) & (0.100) & (0.283) \\ 0.963^{* * *} & 0.727^{* * *} & 1.021^{* * *} & 0.919 \\ (0.108) & (0.206) & (0.113) & (1.079) \\ 0 & 0 & 0 & 0 \\ 0.461^{* * *} & 0.584^{* *} & 0.513^{* * *} & 0.763^{* *} \\ (0.153) & (0.235) & (0.152) & (0.368) \\ -0.265 & 0.253 & -0.049 & 0.317 \\ (0.231) & (0.304) & (0.248) & (0.745)\end{array}$

River Trip $\left(\alpha_{j} \sim N\left(\alpha, \sigma_{\alpha}^{2}\right)\right)$

- Location of Distribution $(\alpha)$

$\begin{array}{cccc}5.388^{* * *} & 4.542^{* * *} & 5.981^{* * *} & 4.856^{* * *} \\ (0.383) & (0.526) & (0.472) & (0.639) \\ 2.459^{* * *} & 3.251^{* * *} & 2.454^{* * *} & 3.184^{* * *} \\ (0.058) & (0.131) & (0.065) & (0.192)\end{array}$

0

0

0

0 
$\begin{array}{lcccc}\text { - Scale of Distribution }\left(\sigma_{\alpha}\right) & 3.146^{* * *} & 0.000^{* * *} & 3.151^{* * *} & 0.000^{* * *} \\ & (0.127) & (0.000) & (0.120) & (0.000)\end{array}$

River Site Qualities:

$\begin{array}{lcccc}\text { Ecological Status: Bad }\left(\beta_{0}\right) & 0 & 0 & 0 & 0 \\ \text { Ecological Status: Poor }\left(\beta_{1}\right) & 0.205 & 0.219 & 0.399 & 0.279 \\ & (0.261) & (0.363) & (0.434) & (0.427) \\ \text { Ecological Status: Good }\left(\beta_{2}\right) & 0.213 & 0.480 & 0.509 & 0.767 \\ & (0.245) & (0.474) & (0.465) & (0.600) \\ \text { Ecological Status: Excellent }\left(\beta_{3}\right) & 0.774^{* *} & 0.735^{*} & 1.194^{* * *} & 0.938^{* *} \\ & (0.321) & (0.400) & (0.407) & (0.418) \\ \text { Land Use: Farmland }\left(\beta_{4}\right) & 0 & 0 & 0 & 0 \\ \text { Land Use: Urban }\left(\beta_{5}\right) & 0.561^{*} & 0.729^{* * *} & 0.580^{* *} & 0.745^{* * *} \\ & (0.287) & (0.267) & (0.281) & (0.266) \\ \text { Land Use: Grassland }\left(\beta_{6}\right) & 0.413^{*} & 0.358 & 0.408^{*} & 0.364 \\ & (0.250) & (0.253) & (0.248) & (0.253) \\ \text { Land Use: Woodland }\left(\beta_{7}\right) & 0.786^{* * *} & 0.860^{* * *} & 0.732^{* * *} & 0.863^{* * *} \\ & (0.260) & (0.247) & (0.257) & (0.246) \\ \text { Population Density }\left(\beta_{8}\right) & -0.300^{* * *} & -0.236^{* * *} & -0.319^{* * *} & -0.236^{* * *} \\ & (0.088) & (0.079) & (0.090) & (0.080)\end{array}$

Nonuse Utility Parameters

River Site Qualities:

Ecological Status: Bad $\left(b_{0}\right)$

Ecological Status: Poor $\left(b_{1}\right)$

Ecological Status: Good $\left(b_{2}\right)$

Ecological Status: Excellent $\left(b_{3}\right)$

Distance Decay: $\left(\lambda_{i} \sim N\left(\lambda, \sigma_{\lambda}^{2}\right)\right)$

- Location of Distribution $(\lambda)$

(0.050) (0.043)

$-0.876^{* * *}$

$0.029^{* * *} \quad 0.031^{* * *}$

$0.027^{* * *}$

(0.007) (0.006)

(0.002)

$0.053^{* * *} \quad 0.059^{* * *}$

$0.053^{* * *}$

(0.013) (0.009)

(0.003)

$0.065^{* * *} \quad 0.070^{* * *}$

$0.065^{* * *}$

(0.016) (0.011)

(0.004)

- Scale of Distribution $\left(\sigma_{\lambda}\right)$

$0.419 * * * \quad 0.596^{* * *}$

\begin{tabular}{lccccc}
\multicolumn{1}{c}{ Relative Scale of CE $\left(\sigma_{S P}\right)$} & $1.651^{* * *}$ & $1.457^{* * *}$ & - & - & - \\
\hline Log Likelihood & $(0.411)$ & $(0.272)$ & & & - \\
$N$ & $-296,768$ & $-320,509$ & $-284,923$ & $-309,424$ & $-9,014$ \\
& 1,794 & 1,794 & 1,794 & 1,794 & 1,708 \\
\hline
\end{tabular}

† Fixed effect model contains 24 additional dummy variables identifying the location of recreational sites in river sub-basins. 
Table V: Welfare Analysis of Sample Valuation of Improvement of all Rivers to Excellent Quality

\begin{tabular}{lccccc}
\hline \multirow{2}{*}{ Model } & \multicolumn{5}{c}{$\begin{array}{c}\text { Mean Welfare Measures } \\
\text { (£2008 per household per year) }\end{array}$} \\
\cline { 2 - 6 } & Median & Mean & $\begin{array}{c}\text { Std. Err. } \\
\text { of Mean }\end{array}$ & $\begin{array}{c}\text { 95\% Confidence } \\
\text { Interval }\end{array}$ \\
\hline Combined Data Model & 20.39 & 20.77 & 2.39 & 16.46 & 25.65 \\
$\quad$ Use-Utility & 3.02 & 3.04 & 0.97 & 1.18 & 4.95 \\
$\quad$ Nonuse Utility & 17.39 & 17.73 & 2.38 & 13.67 & 22.90 \\
Revealed Preference & 3.17 & 3.22 & 0.84 & 1.69 & 5.08 \\
Stated Preference Model & 19.10 & 19.23 & 1.43 & 16.70 & 22.28 \\
\hline
\end{tabular}




\section{Online Appendix: Details of Monte Carlo Analysis}

\section{i. Monte Carlo Environment}

As shown in Figure A1, to execute the Monte Carlo analysis we construct a hypothetical landscape bounded by the unit square and traversed by three rivers. Within the landscape we randomly locate the residences of a sample of 500 individuals (Panel A of Figure A1). For the purposes of evaluating nonuse utility, each river is divided up into 27 stretches of equal length (Panel B of Figure A1). Likewise, 120 recreational sites are located at random along the rivers. In the simulation, river site attributes are limited to ecological status which ranges from bad through to excellent and these are ascribed to sites using a random walk procedure that ensures spatial correlation in water quality (Panel C of Figure A1).
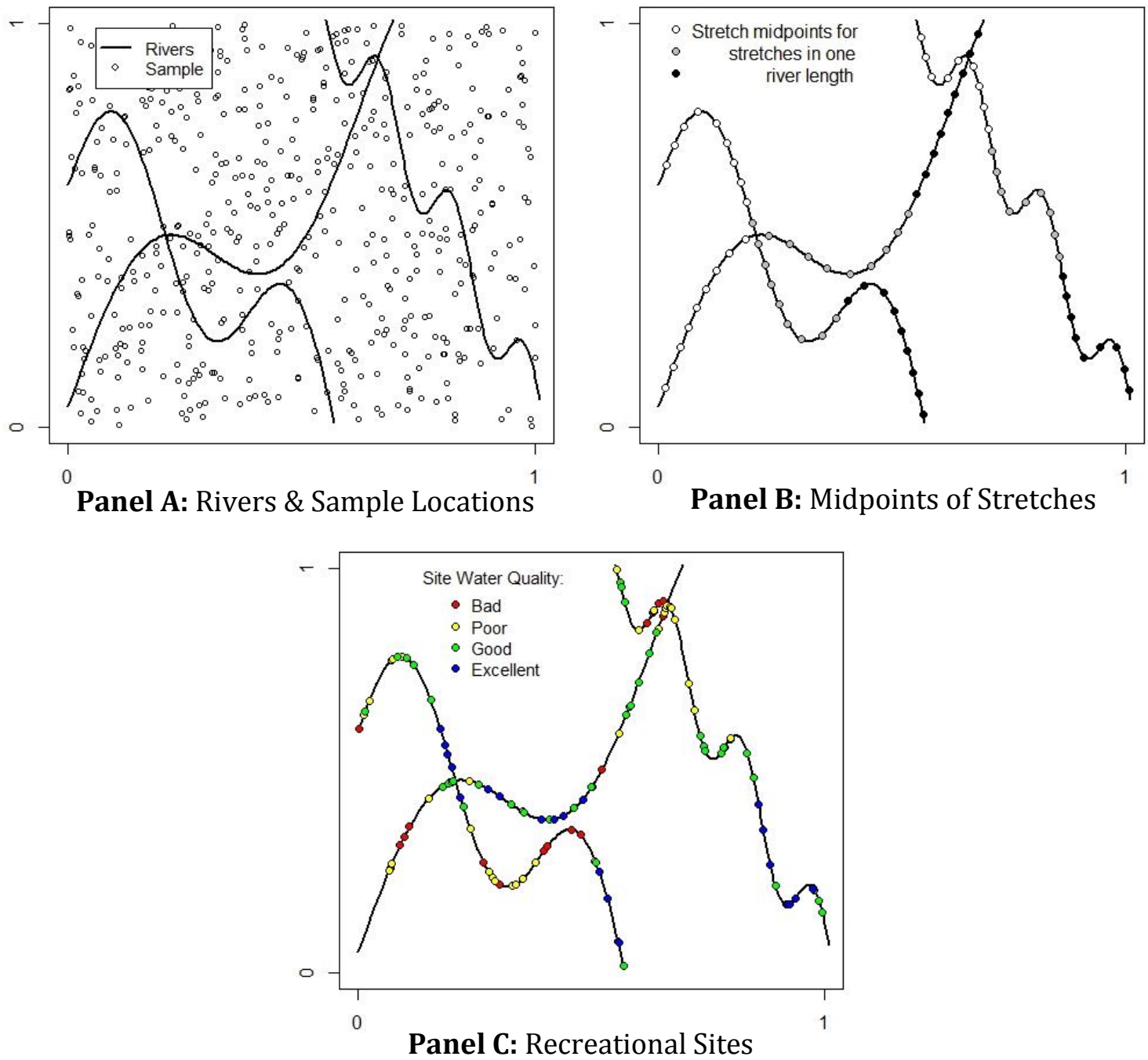

Figure A1: Rivers, Stretches and Sites in the Monte Carlo Analysis 
We assume that there are 50 choice occasions in one year $(T=50)$ and simulate utilities for each recreational option in each period using (22) with particular choices of parameters, a travel cost calculated from the straight line distance from residence to site and random draws of the error term.

An RP dataset is simulated by taking the recreational choice in each period to be the option that provides the highest utility. That choice may change from period to period for one simulated individual since new error terms are drawn each time utilities are evaluated.

To simulate an SP dataset, we created a simple choice experiment design in which the rivers were first divided into nine lengths each comprising nine contiguous river stretches. A scenario was created by randomly attributing a quality to each river length and associating with that scenario a randomly determined cost. One hundred and twenty such scenarios were generated, paired-off so as to create choice tasks and then randomly ascribed into five blocks of twelve tasks. Each simulated individual was assigned to one of the five blocks and their choices in the choice experiment determined by selecting the option providing the highest utility from realisations of the utility function in (22).

\section{ii. Experiment 1}

Our first experiment explores the contribution that the SP data can make to the identification of use-utility parameters. The motivating example here is where a VSCE introduces a level of environmental quality beyond the range observed in the current state of the world.

As explained in the main text, our Monte Carlo experiment consists of a current state of the world in which river quality is limited to the bad, poor and good categories. Accordingly, information on preferences for the 'excellent' level of water quality in both use and nonuse is only provided by responses to a VSCE in which river stretches in some options are ascribed excellent quality.

The key identification problem here arises from the fact that our ability to recover useutility parameters of quality from VSCE data depends primarily on the size of the signal provided by differences in the logsumexp term, $\ln \left(\sum_{j=1}^{J} e^{\left(v_{i, t, s \mid j}^{\text {use }}+v_{i, t, s \mid j}^{\text {other }}\right)}+e^{\left(\alpha_{J+1}+v_{i, t \mid j+1}^{\text {other }}\right)}\right)$, relative to the noise created by the error term (see (21)). Unfortunately, as the use-utility of the outside option $\left(\alpha_{J+1}\right)$ increases, the difference in the logsumexp terms for some particular quality differences 
across two options in a VSCE choice task decreases in magnitude. Accordingly, our ability to identify use-utility parameters from VSCE choice tasks will likely decline as the use-utilty of the outside option increases.

Our first Monte Carlo analysis investigates this identification issue by comparing the distribution of estimates of the model parameters over three experiments where the outside good utility parameter $\left(\alpha_{J+1}\right)$ is fixed at the values of 3,5 , and 7 respectively. The outputs from these Monte Carlo experiments are summarised in Table A1.

Notice that in general at all three values for the use-utility of the outside option, the model returns unbiased and reasonably precise estimates of the preference parameters. In line with our expectations, however, the only exception is the use-utility parameter on excellent quality whose identification deteriorates significantly as use-utility of the outside option increases.

A second experiment was carried out using a similar set up, but this time examining conditions under whether the model can identify a hypothetical bias parameter that again can only be estimated from the SP data. In particular, we imagine that individuals responding to the VSCE may over-estimate their propensity to take trips to environmental areas. Accordingly, we introduce the parameter $\alpha_{J+1}^{S P}$ and set its value to -0.5 . In the analysis of the simulated responses to VSCE choice tasks, $\alpha_{J+1}^{S P}$ is added to $\alpha_{J+1}$ thereby reducing the utility ascribed to choosing the outside option in determining choices in the VSCE.

The results of that Monte Carlo experiment are presented in Table A2. Notice that drawing on information provided by the RP data estimates of the river quality parameters for use utility $\left(\beta_{1}, \beta_{2}\right.$ and $\left.\beta_{3}\right)$ are estimated without bias. Notice, however, that as the size of the utility of the outside good option increases the standard deviation of the Monte Carlo estimates of those parameters also increases. That pattern meets our expectations thatSP data provides less information on use utility parameters as the size of the outside option utility increases. Figure A1 plots out the distribution of $\beta_{1}$ estimates from each Monte Carlo experiment providing visual affirmation of the reduced informational content of the data at larger values for the outside option utility. 
Table AI: Summary of Monte Carlo simulations for different sizes of the utility for the outside option

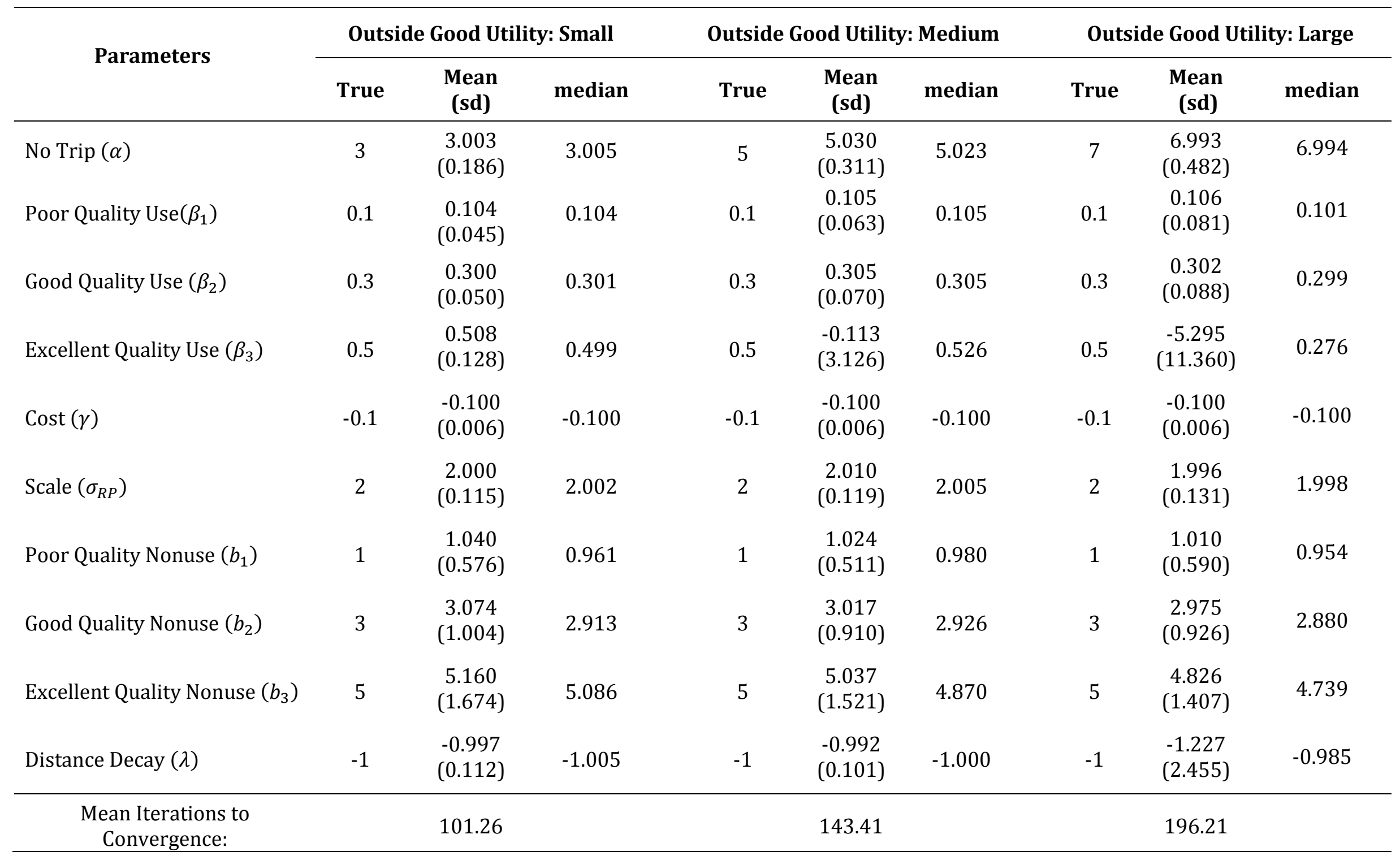


Table A2: Summary of Monte Carlo simulations for different sizes of the utility for the outside option

\begin{tabular}{|c|c|c|c|c|c|c|c|c|c|}
\hline \multirow{2}{*}{ Parameters } & \multicolumn{3}{|c|}{ Outside Good Utility: Small } & \multicolumn{3}{|c|}{ Outside Good Utility: Medium } & \multicolumn{3}{|c|}{ Outside Good Utility: Large } \\
\hline & True & $\begin{array}{c}\text { Mean } \\
\text { (sd) }\end{array}$ & median & True & $\begin{array}{c}\text { Mean } \\
\text { (sd) }\end{array}$ & median & True & $\begin{array}{c}\text { Mean } \\
\text { (sd) }\end{array}$ & median \\
\hline No Trip $(\alpha)$ & 1 & $\begin{array}{c}1.004 \\
(0.068)\end{array}$ & 1.002 & 3 & $\begin{array}{c}2.998 \\
(0.181)\end{array}$ & 2.992 & 5 & $\begin{array}{c}4.992 \\
(0.319)\end{array}$ & 4.996 \\
\hline No Trip $\left(\alpha^{S P}\right)$ & -0.5 & $\begin{array}{l}-0.507 \\
(0.257)\end{array}$ & -0.514 & -0.5 & $\begin{array}{l}-0.484 \\
(0.400)\end{array}$ & -0.501 & -0.5 & $\begin{array}{c}1.884 \\
(5.849)\end{array}$ & -0.605 \\
\hline Poor Quality Use $\left(\beta_{1}\right)$ & 0.1 & $\begin{array}{c}0.102 \\
(0.034)\end{array}$ & 0.101 & 0.1 & $\begin{array}{c}0.103 \\
(0.051)\end{array}$ & 0.102 & 0.1 & $\begin{array}{c}0.100 \\
(0.068)\end{array}$ & 0.102 \\
\hline Good Quality Use $\left(\beta_{2}\right)$ & 0.3 & $\begin{array}{c}0.304 \\
(0.036)\end{array}$ & 0.303 & 0.3 & $\begin{array}{c}0.302 \\
(0.053)\end{array}$ & 0.305 & 0.3 & $\begin{array}{c}0.300 \\
(0.072)\end{array}$ & 0.301 \\
\hline Excellent Quality Use $\left(\beta_{3}\right)$ & 0.5 & $\begin{array}{c}0.502 \\
(0.043)\end{array}$ & 0.500 & 0.5 & $\begin{array}{c}0.502 \\
(0.063)\end{array}$ & 0.500 & 0.5 & $\begin{array}{c}0.498 \\
(0.078)\end{array}$ & 0.493 \\
\hline $\operatorname{Cost}(\gamma)$ & -0.1 & $\begin{array}{l}-0.100 \\
(0.004)\end{array}$ & -0.100 & -0.1 & $\begin{array}{l}-0.100 \\
(0.006)\end{array}$ & -0.100 & -0.1 & $\begin{array}{l}-0.100 \\
(0.006)\end{array}$ & -0.100 \\
\hline Scale $\left(\sigma_{R P}\right)$ & 2 & $\begin{array}{c}1.999 \\
(0.089)\end{array}$ & 1.997 & 2 & $\begin{array}{c}1.997 \\
(0.113)\end{array}$ & 1.995 & 2 & $\begin{array}{c}1.996 \\
(0.123)\end{array}$ & 2.003 \\
\hline Poor Quality Nonuse $\left(b_{1}\right)$ & 1 & $\begin{array}{c}1.065 \\
(0.831)\end{array}$ & 1.003 & 1 & $\begin{array}{c}1.064 \\
(0.662)\end{array}$ & 0.973 & 1 & $\begin{array}{c}1.048 \\
(0.643)\end{array}$ & 0.997 \\
\hline Good Quality Nonuse $\left(b_{2}\right)$ & 3 & $\begin{array}{c}3.141 \\
(1.272)\end{array}$ & 3.003 & 3 & $\begin{array}{c}3.136 \\
(1.248)\end{array}$ & 3.065 & 3 & $\begin{array}{c}3.074 \\
(1.111)\end{array}$ & 3.016 \\
\hline Excellent Quality Nonuse $\left(b_{3}\right)$ & 5 & $\begin{array}{c}5.297 \\
(1.901)\end{array}$ & 5.172 & 5 & $\begin{array}{c}5.224 \\
(1.975)\end{array}$ & 5.066 & 5 & $\begin{array}{c}5.064 \\
(1.692)\end{array}$ & 5.018 \\
\hline Distance Decay $(\lambda)$ & -1 & $\begin{array}{l}-0.997 \\
(0.126)\end{array}$ & -1.007 & -1 & $\begin{array}{l}-0.992 \\
(0.144)\end{array}$ & -1.011 & -1 & $\begin{array}{l}-1.381 \\
(3.001)\end{array}$ & -1.007 \\
\hline Mean Iterations to Convergence: & & 107.00 & & & 112.30 & & & 158.46 & \\
\hline
\end{tabular}




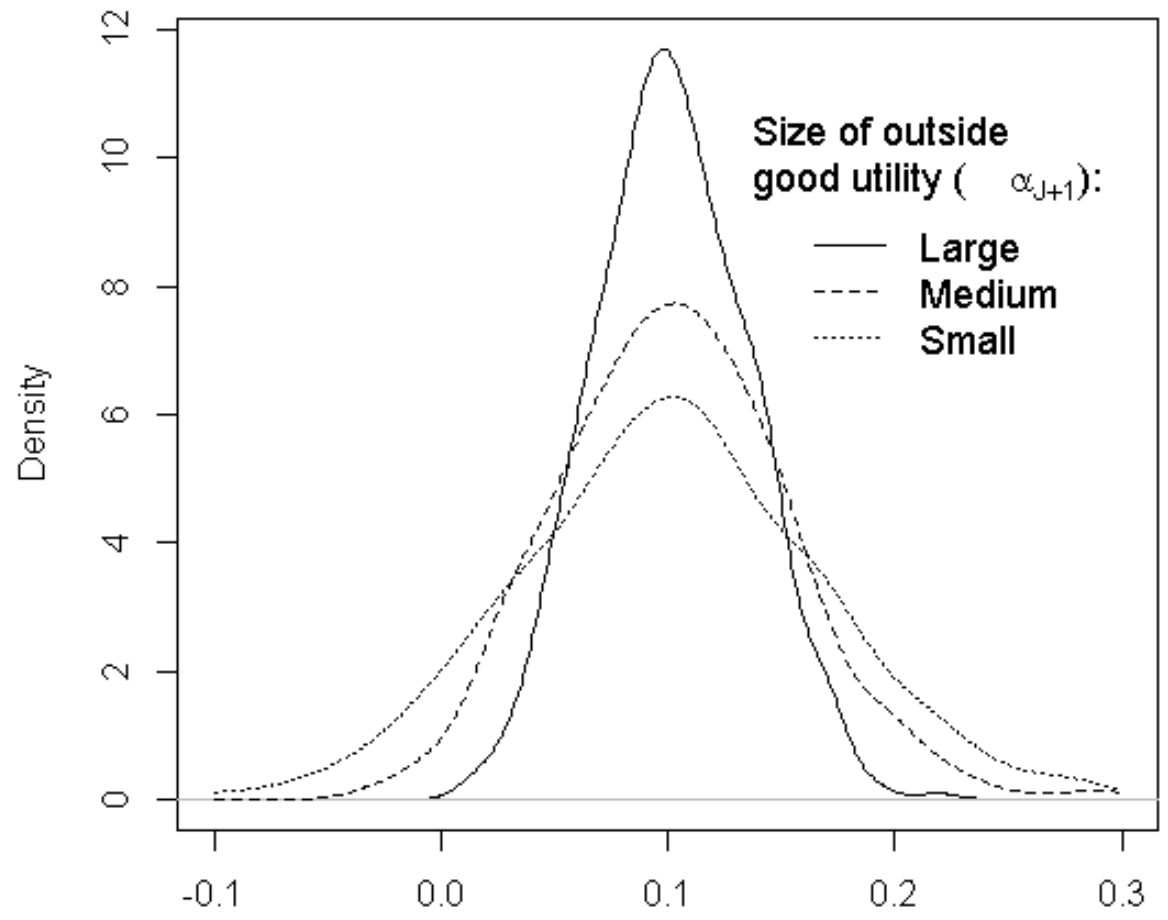

Figure A1: Distribution of poor water quality parameter $\left(\beta_{1}^{0}\right)$ from Monte Carlo experiments differing in the size of the outside option utility parameter $(\alpha)$

With respect to the hypothetical bias parameter $\alpha_{J+1}^{S P}$ we see a similar, though more extreme response to increasing the utility offered by the outside good option. When that utility element is small the hypothetical bias parameter can be successfully recovered solely from the SP data. At the medium level of outside option utility, the parameter is still estimated without appreciable bias, though with a greater degree of variability. Indeed, at the high level of outside option utility the parameter is estimated with such imprecision that the mean value of the parameter over 1000 Monte replicates (1.884) is a long way from the true value (-0.5). Figure A2 plots out the distribution of $\alpha_{J+1}^{S P}$ estimates for each Monte Carlo experiment. The Figure clearly demonstrates the increasing difficulty of identifying the hypothetical bias parameter as an increasingly large utility for the outside good diminishes the informational content of the SP data. 


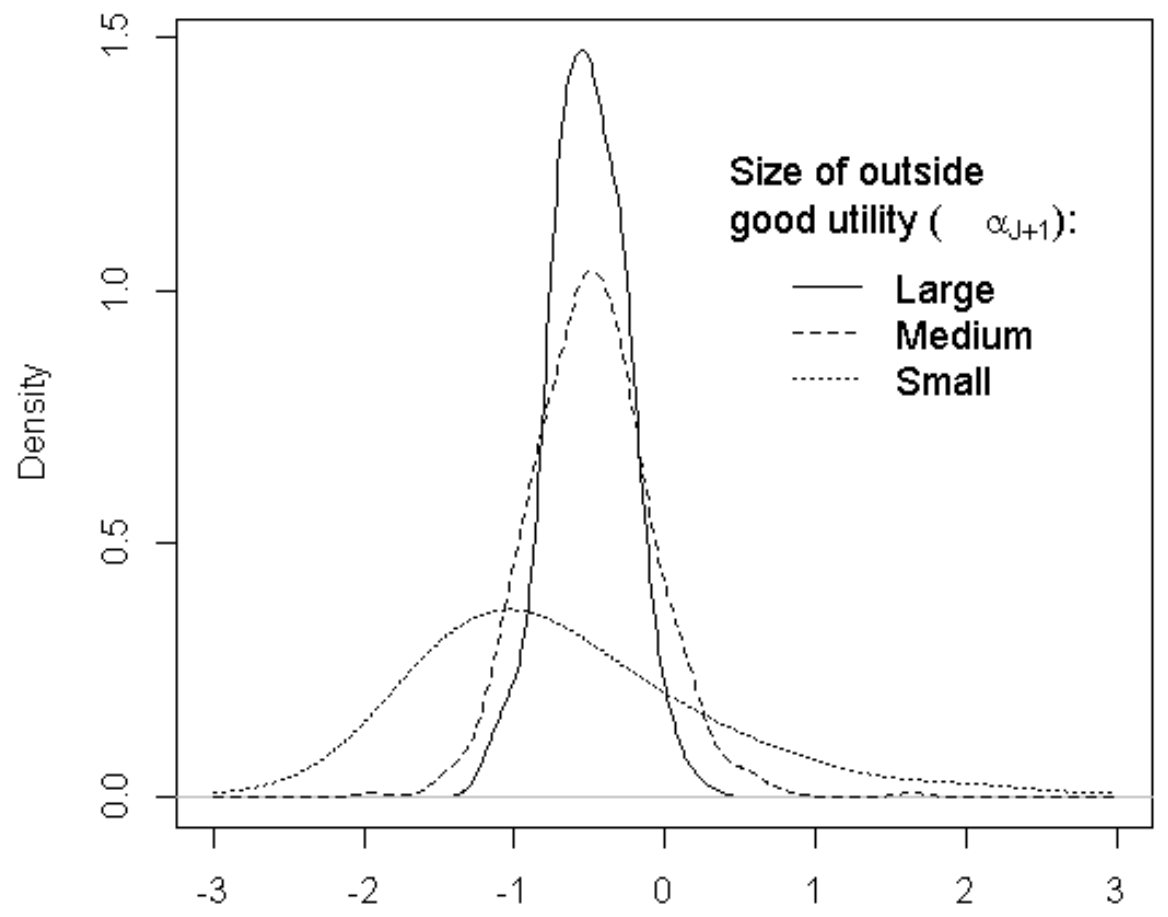

\section{Figure A2: Distribution of hypothetical bias parameter $\left(\alpha^{S P}\right)$ from Monte Carlo experiments differing in the size of the outside option utility parameter $(\alpha)$}

\section{ii. Experiment II}

Our second key concern with the combined-data estimation strategy concerns the model's ability to return estimates of nonuse utility parameters. Put crudely, the estimation strategy for disentangling nonuse values is to observe the degree to which choices in the VSCE differ from the choices that would be expected if determined solely by use value. Of course, the degree to which choices will be influenced by nonuse considerations will depend on the relative size of the nonuse component of utility to the use component of utility. If the nonuse component is relatively large, then we would imagine that the SP data from the choice experiment would give good identification of the nonuse parameters. In contrast, if the nonuse component is relatively small, then identification may be difficult.

Three different sets of parameters were chosen for the Monte Carlo analysis which differed only in the size of the preference parameters determining the nonuse value derived from water qualities. To determine the size of those parameters we selected one scenario at random and evaluated the average gain in welfare that would be realised by the simulated individuals if 
all rivers were improved up to the excellent water quality level. ${ }^{13}$ As shown in Table A3, we chose values for the nonuse parameters that resulted in the nonuse element of this average welfare gain being twice as large as the use element ("Large"), roughly equal to the use element ("Equal") and half the size of the use element ("Small")

Table A3: Monte Carlo Simulation Treatments

\begin{tabular}{|c|c|c|c|c|c|c|}
\hline \multirow{2}{*}{$\begin{array}{l}\text { MC Simulation } \\
\text { Treatment } \\
\text { Name }\end{array}$} & \multicolumn{3}{|c|}{ Nonuse Parameters } & \multicolumn{3}{|c|}{$\begin{array}{l}\text { Average Welfare Change from } \\
\text { Improvement of all Rivers to } \\
\text { Excellent Quality }\end{array}$} \\
\hline & $\begin{array}{l}\text { Poor } \\
\text { Quality } \\
\left(b_{1}\right)\end{array}$ & $\begin{array}{l}\text { Good } \\
\text { Quality } \\
\left(b_{2}\right)\end{array}$ & $\begin{array}{l}\text { Excellent } \\
\text { Quality } \\
\left(b_{3}\right)\end{array}$ & $\begin{array}{l}\text { Nonuse } \\
\text { Element }\end{array}$ & $\begin{array}{c}\text { Use } \\
\text { Element }\end{array}$ & $\begin{array}{c}\text { Ratio of Use } \\
\text { to Nonuse } \\
\text { Element }\end{array}$ \\
\hline Large & 2 & 6 & 10 & 104.3 & 46.9 & 2.22 \\
\hline Equal & 1 & 3 & 5 & 52.1 & 46.9 & 1.11 \\
\hline Small & .5 & 1.5 & 2.5 & 26.1 & 46.9 & 0.56 \\
\hline
\end{tabular}

A summary of the outcomes from the Monte Carlo analysis is presented in Table A4. Observe first that, for all three treatments, the use parameters of the utility function are estimated with almost no bias and with high precision. As expected, the RP data provides a good source of identification for those parameters.

In the case of the 'Large' treatment where nonuse is a major component of utility, the estimator fares very well; the nonuse parameters are estimated with almost no bias and a reasonable level of precision. Moving from the 'Large' to the 'Equal' to the 'Small' treatments, however, introduces increasing bias into the nonuse parameters. The most significant bias is in the distance-decay parameter $(\lambda)$ whose mean value from the simulations significantly increases in absolute value. To better understand that finding, Figure A3 provides a density plot of the $\lambda$ values estimated in each Monte Carlo treatment.

\footnotetext{
${ }^{13}$ The randomly chosen scenario had 2 river lengths of excellent quality, four of good quality, three of poor quality but no bad quality river lengths.
} 
Table A4: Summary of Monte Carlo simulations for different relative sizes of the nonuse component of utility

\begin{tabular}{|c|c|c|c|c|c|c|c|c|c|}
\hline \multirow{2}{*}{ Parameters } & \multicolumn{3}{|c|}{ Nonuse Component: Large } & \multicolumn{3}{|c|}{ Nonuse Component: Equal } & \multicolumn{3}{|c|}{ Nonuse Component: Small } \\
\hline & True & $\begin{array}{c}\text { Mean } \\
\text { (sd) }\end{array}$ & median & True & $\begin{array}{c}\text { Mean } \\
\text { (sd) }\end{array}$ & median & True & $\begin{array}{c}\text { Mean } \\
\text { (sd) }\end{array}$ & median \\
\hline No Trip $(\alpha)$ & 1 & $\begin{array}{l}1.001 \\
(0.072)\end{array}$ & 0.999 & 1 & $\begin{array}{c}0.997 \\
(0.068)\end{array}$ & 0.995 & 1 & $\begin{array}{c}0.996 \\
(0.070)\end{array}$ & 0.994 \\
\hline Poor Quality Use $\left(\beta_{1}\right)$ & 0.1 & $\begin{array}{c}0.101 \\
(0.036)\end{array}$ & 0.099 & 0.1 & $\begin{array}{c}0.107 \\
(0.036)\end{array}$ & 0.106 & 0.1 & $\begin{array}{c}0.104 \\
(0.034)\end{array}$ & 0.105 \\
\hline Good Quality Use $\left(\beta_{2}\right)$ & 0.3 & $\begin{array}{c}0.301 \\
(0.037)\end{array}$ & 0.301 & 0.3 & $\begin{array}{c}0.311 \\
(0.044)\end{array}$ & 0.307 & 0.3 & $\begin{array}{c}0.308 \\
(0.039)\end{array}$ & 0.307 \\
\hline Excellent Quality Use $\left(\beta_{3}\right)$ & 0.5 & $\begin{array}{c}0.501 \\
(0.044)\end{array}$ & 0.500 & 0.5 & $\begin{array}{c}0.514 \\
(0.055)\end{array}$ & 0.507 & 0.5 & $\begin{array}{c}0.510 \\
(0.047)\end{array}$ & 0.506 \\
\hline $\operatorname{Cost}(\gamma)$ & -0.1 & $\begin{array}{l}-0.100 \\
(0.005)\end{array}$ & -0.100 & -0.1 & $\begin{array}{l}-0.099 \\
(0.006)\end{array}$ & -0.099 & -0.1 & $\begin{array}{l}-0.099 \\
(0.005)\end{array}$ & -0.099 \\
\hline Scale $\left(\sigma_{R P}\right)$ & 2 & $\begin{array}{c}2.004 \\
(0.100)\end{array}$ & 2.004 & 2 & $\begin{array}{c}1.975 \\
(0.113)\end{array}$ & 1.981 & 2 & $\begin{array}{c}1.980 \\
(0.101)\end{array}$ & 1.981 \\
\hline Poor Quality Nonuse $\left(b_{1}\right)$ & 2 & $\begin{array}{c}2.051 \\
(0.733)\end{array}$ & 2.012 & 1 & $\begin{array}{c}1.070 \\
(1.129)\end{array}$ & 0.924 & 0.5 & $\begin{array}{c}0.700 \\
(1.449)\end{array}$ & 0.485 \\
\hline Good Quality Nonuse $\left(b_{2}\right)$ & 6 & $\begin{array}{c}6.098 \\
(1.223)\end{array}$ & 5.933 & 3 & $\begin{array}{c}3.195 \\
(1.420)\end{array}$ & 3.062 & 1.5 & $\begin{array}{c}1.830 \\
(1.765)\end{array}$ & 1.635 \\
\hline Excellent Quality Nonuse $\left(b_{3}\right)$ & 10 & $\begin{array}{l}10.198 \\
(1.871)\end{array}$ & 10.119 & 5 & $\begin{array}{c}5.316 \\
(2.000)\end{array}$ & 5.135 & 2.5 & $\begin{array}{c}2.993 \\
(1.977)\end{array}$ & 2.826 \\
\hline Distance Decay $(\lambda)$ & -1 & $\begin{array}{l}-0.999 \\
(0.058)\end{array}$ & -1.000 & -1 & $\begin{array}{l}-6.634 \\
(20.52)\end{array}$ & -1.025 & -1 & $\begin{array}{c}-20.68 \\
(100.24)\end{array}$ & -1.084 \\
\hline
\end{tabular}




\begin{tabular}{|c|c|c|c|c|c|c|c|c|c|}
\hline Welfare & 151.22 & $\begin{array}{l}152.22 \\
(10.48)\end{array}$ & 151.86 & 99.08 & $\begin{array}{c}96.60 \\
(12.64)\end{array}$ & 98.34 & 72.99 & $\begin{array}{c}70.71 \\
(10.11)\end{array}$ & 70.47 \\
\hline Mean Iterations to Convergence: & & 97.62 & & & 137.10 & & & 132.56 & \\
\hline
\end{tabular}




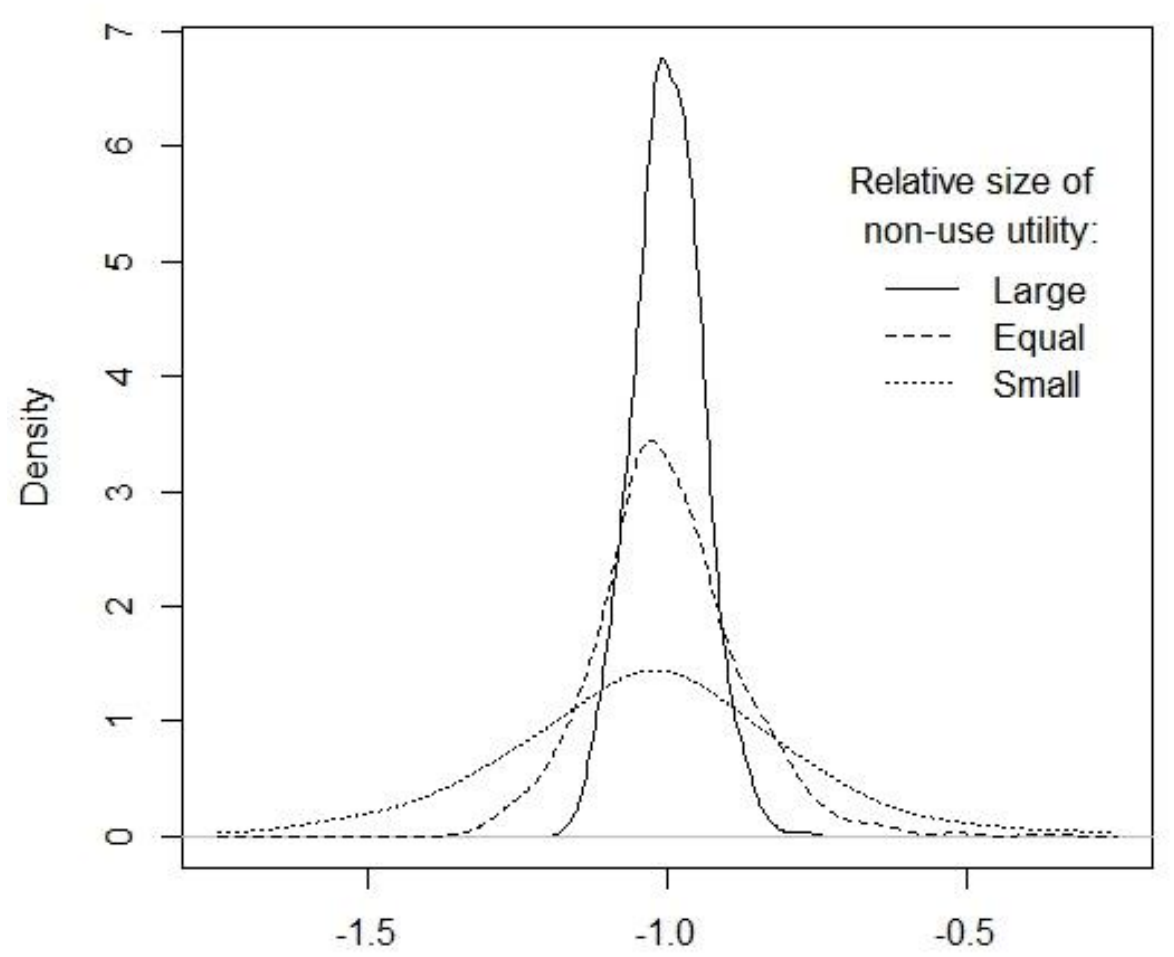

Figure A3: Distribution of distance-decay parameter $(\lambda)$ from Monte Carlo experiments differing in the relative size of the nonuse utility elements

It is apparent from Figure A3, that for all three treatments the distributions are centred on the true value of -1 . What is also apparent from Figure A3 is the fact that as the relative size of the nonuse utility element declines the precision with which the distance-decay parameter is estimated also declines. Indeed, a more detailed examination of the data shows that while in the 'Large' treatment the distance-decay parameters estimated in the simulations fall within the range -0.770 to -1.163 , the 'Equal' and 'Small' treatments are characterised by a significant extension to the left hand tail of the distribution. Indeed in the 'Equal' treatment $88 \%$ of the parameter estimates lie in the range -0.368 to -1.325 the remaining $12 \%$ span the range -12.539 to -180.630 . Likewise in the 'Small' treatment $19 \%$ of the estimates fall in the range -10.150 to 2,651.6. It appears that when the contribution of nonuse is relatively small, the estimator has difficulties identifying the nonuse parameters for some realisations of the data. In those cases, we can assume that the nonuse elements of utility make little difference to the choices made in the choice experiment. Accordingly, the estimator tends towards a distance-decay parameter that, in effect, discounts nonuse utility away to practically zero. 
Interestingly, the difficulties in estimating the nonuse components of utility do not appear to carry over into the estimation of welfare impacts. Observe from the second to last row of Table A4 that the average welfare gain from improving all rivers to excellent quality from our selected baseline scenario is estimated with relatively little bias. Figure A4, confirms that finding showing that the distributions of welfare estimates from the simulations are centred around their true values with a similar level of precision being realised in all three treatments.

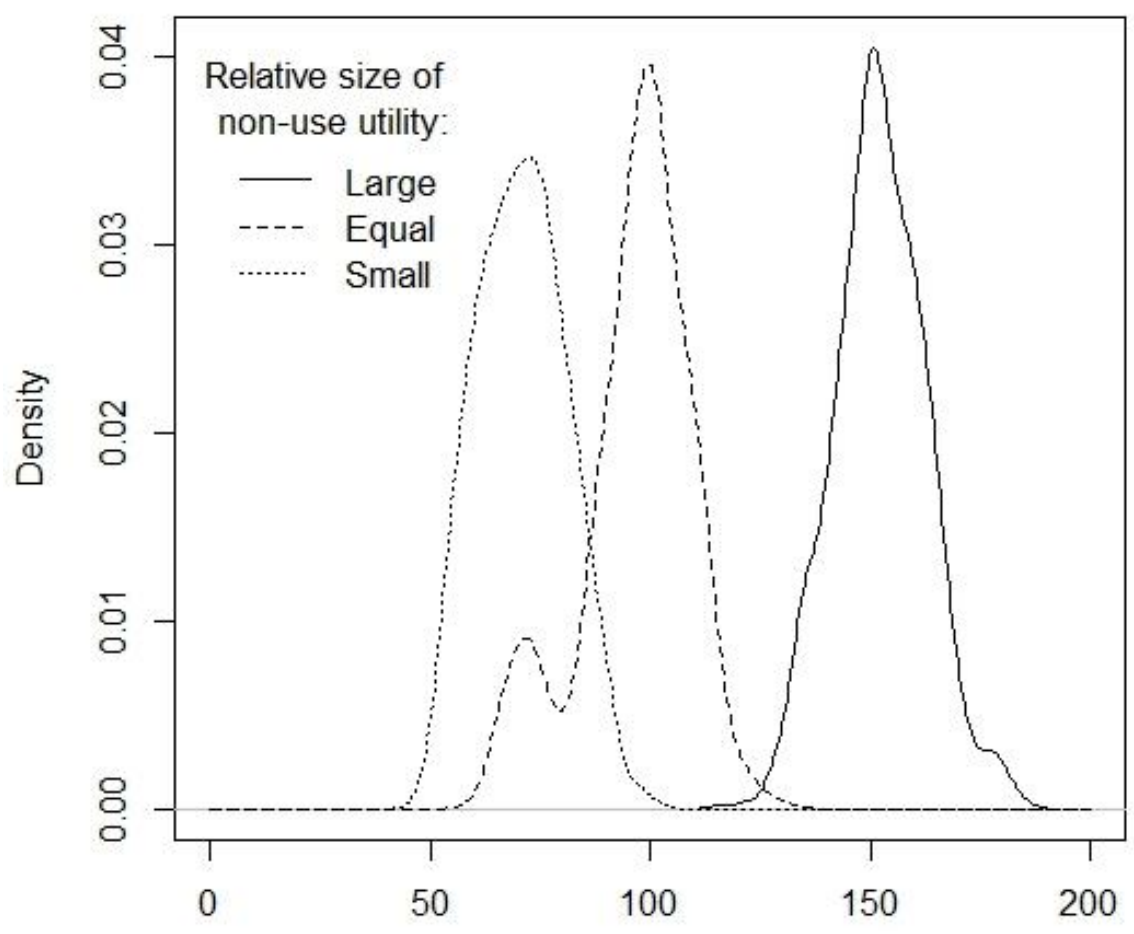

\section{Figure A4: Distribution of welfare gains from Monte Carlo experiments differing in the relative size of the nonuse utility elements}

\section{Experiment III}

As described in the paper our final experiment seeks to understand the possible consequences of using a reduced-form specification on just the SP data rather than applying the full structural model to the combined RP and SP data. To maintain relative comparability, suppose that the approach adopted was to estimate a utility function that assumed the value derived from a choice experiment scenario could be approximated as the weighted sum of river qualities across the $M$ river stretches in that scenario according to; 


$$
u_{i, t, s}=\sum_{m=1}^{M}\left(d_{i, m}+1\right)^{\lambda_{0}} \boldsymbol{x}_{m, s} \boldsymbol{b}_{\mathbf{0}}+\gamma_{0}\left(I_{i}-p_{s} / T\right)+\varepsilon_{i, j, t, s} \quad(\forall i, t, s)
$$

Notice that (A1) is simply our specification of the nonuse elements of the utility function. In applying (A1) to data in which choices are made according to both use and nonuse considerations, however, we might expect the water quality parameters, $\boldsymbol{b}_{\mathbf{0}}$, to pick up the combined effect of water quality on both use and nonuse. Likewise, the distance-decay parameter, $\lambda_{0}$, will pick up not only the effect of distance on nonuse utility but also the effect of travel costs on use utility. The question we wish to answer is whether (A1) provides a sufficiently close approximation to the full structural model that the added complexity of estimating the full structural model might be considered an unnecessary luxury. Table A5 summarizes a Monte Carlo experiment used to explore that question.

Table A5: Summary of Monte Carlo simulations for mis-specified model applied to stated preference data

\begin{tabular}{|c|c|c|c|c|c|c|}
\hline \multirow{2}{*}{ Parameters } & \multicolumn{2}{|c|}{ Nonuse: Large } & \multicolumn{2}{|c|}{ Nonuse: Equal } & \multicolumn{2}{|c|}{ Nonuse: Small } \\
\hline & True & $\begin{array}{c}\text { Mean } \\
\text { (sd) }\end{array}$ & True & $\begin{array}{c}\text { Mean } \\
\text { (sd) }\end{array}$ & True & $\begin{array}{c}\text { Mean } \\
\text { (sd) }\end{array}$ \\
\hline $\operatorname{Cost}(\gamma)$ & -0.1 & $\begin{array}{l}-0.101 \\
(0.006)\end{array}$ & -0.1 & $\begin{array}{l}-0.102 \\
(0.006)\end{array}$ & -0.1 & $\begin{array}{c}-0.1023 \\
(0.006)\end{array}$ \\
\hline Poor Quality $\left(b_{1}\right)$ & 2 & $\begin{array}{c}4.953 \\
(0.785)\end{array}$ & 1 & $\begin{array}{c}3.541 \\
(0.763)\end{array}$ & 0.5 & $\begin{array}{c}2.809 \\
(0,736)\end{array}$ \\
\hline Good Quality $\left(b_{2}\right)$ & 6 & $\begin{array}{l}15.152 \\
(1.337)\end{array}$ & 3 & $\begin{array}{l}11.049 \\
(1.175)\end{array}$ & 1.5 & $\begin{array}{c}8.941 \\
(1.037)\end{array}$ \\
\hline Excellent Quality $\left(b_{3}\right)$ & 10 & $\begin{array}{l}26.435 \\
(2.131)\end{array}$ & 5 & $\begin{array}{l}19.666 \\
(1.791)\end{array}$ & 2.5 & $\begin{array}{l}16.211 \\
(1.572)\end{array}$ \\
\hline Distance Decay $(\lambda)$ & -1 & $\begin{array}{l}-1.169 \\
(0.028)\end{array}$ & -1 & $\begin{array}{l}-1.195 \\
(0.033)\end{array}$ & -1 & $\begin{array}{l}-1.214 \\
(0.037)\end{array}$ \\
\hline Welfare & 151.22 & $\begin{array}{l}166.08 \\
(11.35)\end{array}$ & 99.08 & $\begin{array}{l}115.38 \\
(8.623)\end{array}$ & 72.99 & $\begin{array}{c}90.30 \\
(7.538)\end{array}$ \\
\hline
\end{tabular}

The Monte Carlo analyses reported in Table A5 use exactly the same simulations as those underpinning Table A4. Observe that for all three treatments, the parameters on the quality 
variables and the distance decay show the bias that would be expected if the parameters were picking up elements relating to use utility as well as to nonuse utility. More importantly observe the welfare estimates shown in the final row of Table A5. For each treatment these welfare estimates are biased upwards with the size of bias in terms of standard deviations from the true value increasing from 1.31 for the 'Large' treatment, to 1.89 for the 'Equal' treatment, to 2.29 for the 'Small' treatment. We conclude that relying on approximating reduced-form equations may result in significant errors in the calculation of welfare effects. Our Monte Carlo analysis lends support to the idea that, if possible, econometric models should be carefully constructed to reflect the underlying structure of the data-generating process. 